\title{
A 2.4 GHz CMOS Class-F Power Amplifier With Reconfigurable Load-Impedance Matching
}

\author{
Mitra Gilasgar, Antoni Barlabé, Member, IEEE, and Lluís Pradell, Member, IEEE
}

\begin{abstract}
A novel reconfigurable CMOS class-F power amplifier (PA) at $2.4 \mathrm{GHz}$ is proposed in this paper. It is able to match the output load variations mainly due to the effect of hand and head on a mobile phone. The effect of load variation on PAE, output power and distortion is compensated by reconfiguring the output network using an impedance tuner. The tuner controls the output matching at fundamental frequency without affecting the class-F harmonic tuning up to $3^{\text {rd }}$ harmonic. To the authors' knowledge, this is the first design of a CMOS class-F PA addressed to compensate the effect of load variation. Measurement results for $50 \Omega$ load impedance show a maximum PAE of $26 \%$, and maximum output power of $19.2 \mathrm{dBm}$. The measured total harmonic distortion is $4.9 \%$. Measurement results for load values other than $50 \Omega$ show that PAE increases from $6.5 \%$ (not-tuned PA) up to $19.9 \%$ (tuned PA) with the same output power (19.2 dBm). Tuning also reduces the ACLR by $5 \mathrm{~dB}$ and the spectral regrowth of a WiFi signal at the PA output. The size of the fabricated chip is $1.6 \mathrm{~mm} \times 1.6 \mathrm{~mm}$.
\end{abstract}

Index Terms-Reconfigurable, class-F, power amplifier (PA), CMOS, impedance tuner

\section{INTRODUCTION}

$\mathrm{P}$ OWER amplifiers (PAs) are critical blocks in wireless communication systems because of their high power consumption. The demand for longer battery lifetime, smaller size and lower cost brings a great need for PAs to be highly efficient and integrated with other devices in a single chip [1]. The PA is the most difficult block to implement in CMOS [2] due to the low breakdown voltage, the conductive substrate, and the sheet-resistance of the poly silicon that limit the output power and efficiency.

Switching PAs [3] such as class-E [4]-[6] and class-F [7][10], have a minimum overlap between drain voltage and current waveforms, resulting in low power consumption and

Manuscript received September 7, 2017; revised May 25, 2018; accepted June 21, 2018. This work was supported in part by the Spanish MEC under Projects TEC2013-48102-C2-1-P, TEC2016-78028-C3-1-P and grant BES2011-051305, and the Unidad de Excelencia Maria de Maeztu MDM-20160600, financed by the AEI, Spain.

M. Gilasgar was with the Department of Signal Theory and Communications, Universitat Politècnica de Catalunya (UPC), 08034, Barcelona, Spain. She is now with Ampleon Netherlands B.V., 6534AV Nijmegen, The Netherlands (e-mail: mitra.gilasgar@tsc.upc.edu).

A. Barlabé is with the Department of Signal Theory and Communications, Universitat Politècnica de Catalunya (UPC), 08034, Barcelona, Spain (e-mail: barlabe@ @tsc.upc.edu)

L. Pradell is with the Department of Signal Theory and Communications, Universitat Politècnica de Catalunya (UPC), 08034, Barcelona, Spain (e-mail: pradell@tsc.upc.edu). high efficiency. Although the class-E load network (consisting of one resonator) is simpler than class-F (consisting of multiple resonators), the voltage swing on the drain of a classE PA can reach up to 3.6 times the drain bias voltage $\mathrm{V}_{\mathrm{DD}}$, while only 2 times $V_{D D}$ is possible for a class-F PA. Therefore, for the implementation on low breakdown technologies such as CMOS, a class-F PA is more suitable. A few fully integrated class-F PAs in CMOS have been reported [11][14]. To overcome the CMOS substrate limitation [15], lowloss matching networks using off-chip components have been proposed [16]-[19]. Furthermore, techniques such as power combining [14], [20] and stacked transistors [21] are used to increase the output power.

In wireless communications networks it is desired that RF front ends and consequently PAs could adapt to different conditions such as change in bias, frequency, load impedance or power. Load impedance variation happens when a user holds the mobile phone and the strong interaction between head, hand and antenna causes a change in antenna impedance [22], [23] leading to a reduced performance. In [24], a notintegrated tunable output matching network (OMN) for reconfigurable $\mathrm{RF}$ frontends is presented which includes harmonic tuning. Some other topologies for adaptive impedance tuners are presented in [25], [26].

Recent RF PAs with reconfigurable impedance tuning networks are aimed for multi-band operation [13], [20], [27], [28]. Other works are aimed for output power control using on-chip power combiners [29], bondwires and switched capacitors [30], or a combination of an adaptive power supply and impedance tuning using varactor diodes [31]. Techniques for adaptive control of impedance matching networks which provide automatic compensation of antenna mismatch are presented in [32]. In [33], a dynamic load trajectory manipulation technique is presented to enhance the efficiency of a CMOS Class-G PA, but with fixed load (antenna) impedance. In [34], a reconfigurable Doherty PA with transformer-based networks is presented which provides robust PA operation against load mismatches up to 2:1 VSWR. Among all the reported CMOS PAs only [13], [14] are reconfigurable class-F PAs, however the reconfiguration is not in load impedance but in frequency [13] or output power [14].

In this paper a novel reconfigurable CMOS class-F PA working at $2.4 \mathrm{GHz}$ is proposed which can match different load impedance values. The effect of PA load variation on power-added efficiency (PAE), output power and distortion is 
compensated by reconfiguring the output network using an impedance tuner which includes two MOS variable capacitors. The tuner controls the output matching at fundamental frequency without affecting the class-F harmonic tuning up to $3^{\text {rd }}$ harmonic.

\section{Proposed ReCONFIGURABLE Class-F PA DESIGN}

\section{A. Load-pull analysis}

In an ideal class-F PA, the load impedance seen by the transistor should be a short circuit at even harmonics and an open circuit at odd harmonics. In a real PA, the active device is not an ideal switch, and therefore the optimum load impedances at harmonic frequencies are not short or open circuits. The load impedance values at the output of transistor at fundamental and harmonic frequencies which give highest power-added efficiency (PAE) or highest output power or a tradeoff between them can be derived from a load-pull analysis using the nonlinear model of the transistor. The active device in this design is a $3.3 \mathrm{~V}$ thick oxide $0.18 \mu \mathrm{m}$ NMOS transistor available in $\mathrm{TSMC}^{\mathrm{TM}}$ CMOS technology. The transistor size is $64 \times 8 \mu \mathrm{m}$ (64 fingers with a length of $8 \mu \mathrm{m}$ each). The output power and PAE contours of this device obtained from load-pull at fundamental frequency $(2.4 \mathrm{GHz})$ are shown in Fig. 1(a). It shows that a maximum PAE of $30.1 \%$ can be achieved for a load impedance $\mathrm{Z}_{\mathrm{L} 1}=42+\mathrm{j} 21.6$ $\Omega$, which has been selected for the PA design. The same procedure is done for $2^{\text {nd }}$ harmonic (Fig. 1(b)) and $3^{\text {rd }}$ harmonic (Fig. 1(c)). To reduce distortion (harmonic content at the amplifier output), harmonic loads near to those of an ideal class-F operation were chosen, even though (from Fig. $1(b))$ the $2^{\text {nd }}$ harmonic load does not show optimal PAE/output power. With the above criteria, the selected load impedance values are $\mathrm{Z}_{\mathrm{L} 2}=2.5-\mathrm{j} 3.7 \Omega$ and $\mathrm{Z}_{\mathrm{L} 3}=11.3+\mathrm{j} 53 \Omega$, respectively. The $3^{\text {rd }}$ harmonic load is shifted from an ideal open circuit due to the transistor drain capacitance. This way a class-F operation is guaranteed providing a trade-off between $\mathrm{PAE}$, output power and distortion. The OMN proposed in Section II.B (Fig. 2) is designed to give these impedances at the desired frequencies.

From Fig. 1(c) it is apparent that PAE and output power are much insensitive to the impedance at $3^{\text {rd }}$ harmonic and therefore (as studied in detail in Section II.C) to variations of this impedance produced by the reconfigurable OMN and different amplifier load impedances. The above calculations take into account loss in the matching networks. The effect of loss in the PA performance is further analyzed in Sections II.C and III.

\section{B. Output matching network}

The proposed OMN to achieve class-F operation using lumped elements is shown in Fig. 2(a). It consists of a harmonics filter and a CLC pi-shaped matching network at fundamental frequency $\left(f_{0}\right)$ with variable capacitors (tuner).

The harmonics filter should provide an open circuit for odd harmonics and a short circuit for even harmonics in an ideal class-F operation. In that case, the parallel inductance $\mathrm{L}_{\mathrm{d}}$ and a

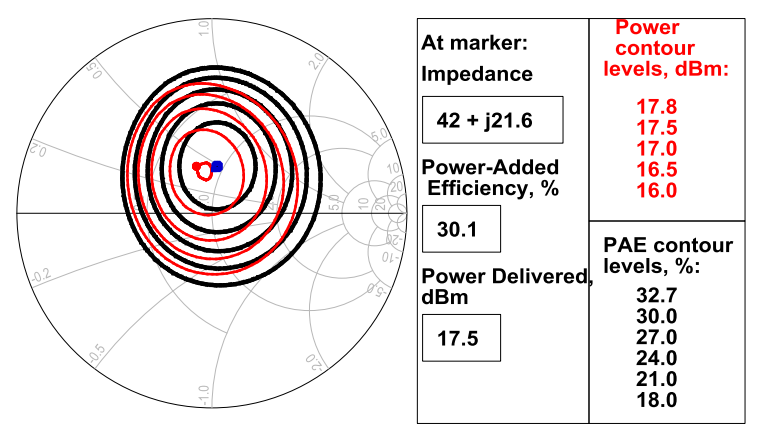

(a)

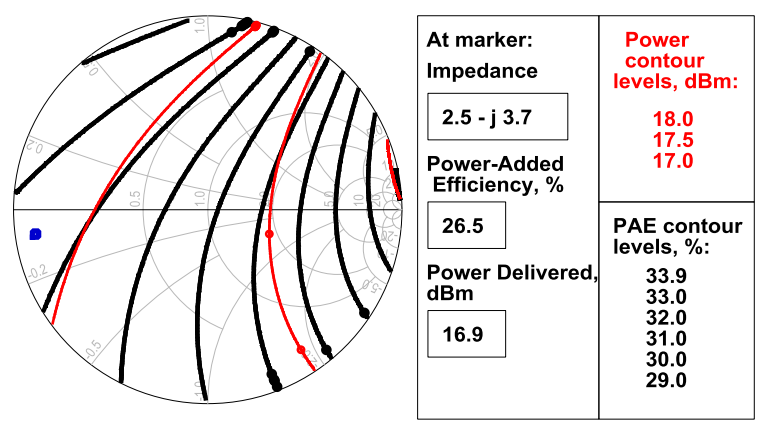

(b)

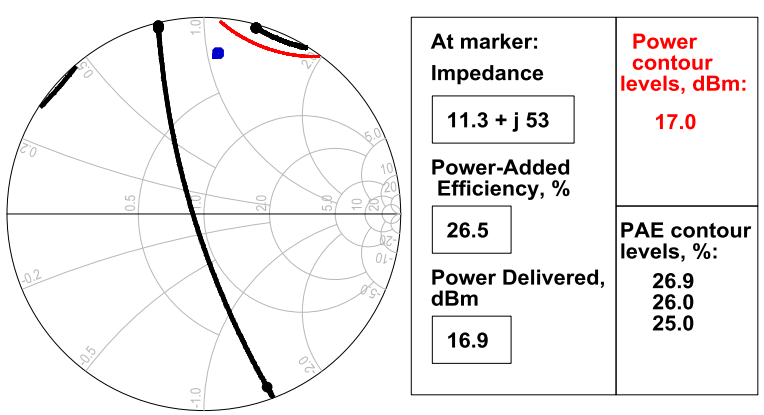

(c)

Fig. 1. Constant PAE (thin) and output power (thick) contours at (a) Fundamental $(2.4 \mathrm{GHz}),(\mathrm{b}) 2^{\text {nd }}$ harmonic $(4.8 \mathrm{GHz})$, and (c) $3^{\text {rd }}$ harmonic $(7.2$ $\mathrm{GHz})$.

series capacitor $\mathrm{C}_{\mathrm{s}}$ are not required and, since in our design the operation is limited to the $2^{\text {nd }}$ and $3^{\text {rd }}$ harmonics, the series LC resonator built by $\mathrm{L}_{2}$ and $\mathrm{C}_{2}$ resonates at $2 f_{0}$, providing a short circuit to the $2^{\text {nd }}$ harmonic. The resonator $\mathrm{L}_{3} \mathrm{C}_{3}$ provides an open circuit at $3 f_{0}$. At frequencies well below its respective resonant frequency, resonator $\mathrm{L}_{2} \mathrm{C}_{2}$ behaves as a capacitor, and resonator $\mathrm{L}_{3} \mathrm{C}_{3}$ behaves as an inductor, giving a low pass filter that will have a small influence on the matching network behavior.

In a realistic class-F operation, since the optimum load impedances at harmonics are not short or open circuits but the values obtained previously from load-pull analysis (Section II.A), the harmonics filter is modified by adding the parallel inductance $\mathrm{L}_{\mathrm{d}}$ and the series capacitor $\mathrm{C}_{\mathrm{s}}$. In that case, the equivalent circuit at $2 f_{0}$ is shown in Fig. 2(b). It can be observed that the filter for the $2^{\text {nd }}$ harmonic is uncoupled from the matching network, thus adjusting the variable capacitors will not have any effect on the $2^{\text {nd }}$ harmonic load. At $3 f_{0}$ the equivalent circuit is presented in Fig. 2(c), which is also uncoupled from the matching network section. 
The design process begins by choosing appropriate values for the resonator components $\left(\mathrm{L}_{2}, \mathrm{C}_{2}\right.$ and $\left.\mathrm{L}_{3}, \mathrm{C}_{3}\right)$. Considering their respective resonance frequencies the values of the products $\mathrm{L}_{2} \mathrm{C}_{2}$ and $\mathrm{L}_{3} \mathrm{C}_{3}$ are obtained. Inductors are chosen so as to minimize the chip area with optimum $\mathrm{Q}$ factor. Then the capacitor values are fixed. Values of $\mathrm{C}_{\mathrm{s}}$ and $\mathrm{L}_{\mathrm{d}}$ are obtained from analysis of the circuit in Fig. 2(b) and 2(c) by solving

$$
\begin{aligned}
& a C_{s}^{2}+b C_{s}+c=0 \\
& L_{d}=\frac{X_{2}}{4 X_{2} \omega_{0}^{2} C_{s}+2 \omega_{0}}
\end{aligned}
$$

where

$$
\begin{aligned}
& a=5 \omega_{0} X_{2} X_{3} \\
& b=\left(5 \omega_{0} X_{2} X_{3} C_{2}-\frac{15}{4} X_{2}+\frac{5}{2} X_{3}\right) \\
& c=3 X_{2} C_{2}-2 X_{3} C_{2}
\end{aligned}
$$

being $X_{2}$ and $X_{3}$ the transistor optimum load reactances at $2^{\text {nd }}$ and $3^{\text {rd }}$ harmonic respectively obtained previously by load-pull analysis, and $\omega_{0}$ the fundamental angular frequency. In the above derivation, the circuit elements are considered lossless, and therefore only the imaginary part of $\mathrm{Z}_{\mathrm{L} 2}$ and $\mathrm{Z}_{\mathrm{L} 3}$ is taken into account. In this design the following values were chosen for the resonator elements: $\mathrm{C}_{2}=7 \mathrm{pF}, \mathrm{L}_{2}=0.06 \mathrm{nH}, \mathrm{C}_{3}=0.6$ $\mathrm{pF}, \mathrm{L}_{3}=0.8 \mathrm{nH}$. The values of $\mathrm{C}_{\mathrm{s}}$ and $\mathrm{L}_{\mathrm{d}}$ obtained using (1) are $\mathrm{C}_{\mathrm{s}}=9 \mathrm{pF}, \mathrm{L}_{\mathrm{d}}=2.3 \mathrm{nH}$.

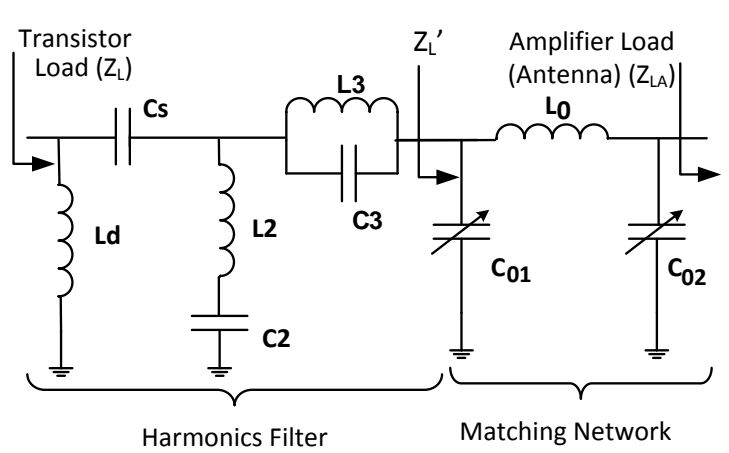

(a)

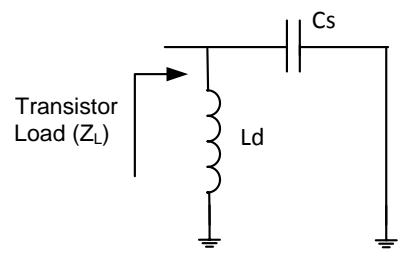

(b)

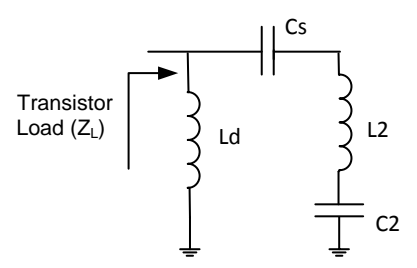

(c)
Fig. 2. (a) Proposed output matching network for the Class-F PA using lumped elements. (b) Equivalent circuit at $2 f_{0}$. (c) Equivalent circuit at $3 f_{0}$.

Next step is the design of the pi-shaped matching network (tuner) at fundamental frequency (elements $\mathrm{C}_{01}, \mathrm{~L}_{0}$ and $\mathrm{C}_{02}$ in Fig. 2). With such a circuit topology any arbitrary load impedance can be transformed into the optimal transistor load impedance at fundamental frequency $\left(\mathrm{Z}_{\mathrm{L} 1}\right)$. To calculate $\mathrm{C}_{01}$, $\mathrm{L}_{0}$ and $\mathrm{C}_{02}$, the input impedance at fundamental ( $Z_{\mathrm{L} 1}^{\prime}$ in Fig. 2(a)) is first calculated from the required transistor load impedance $Z_{\mathrm{L} 1}=42+\mathrm{j} 21.6 \Omega$, by taking into account the effect of the harmonics filter elements. Next, the real and imaginary part of the normalized input admittance $\overline{Y_{\mathrm{L} 1}^{\prime}}=1 / \overline{Z_{\mathrm{L} 1}^{\prime}}$ are expressed as

$$
\begin{aligned}
& \operatorname{Re}\left(\overline{Y_{\mathrm{L} 1}^{\prime}}\right)=\frac{1+\bar{X} \cdot\left(\overline{B_{1}}-\overline{B_{2}}\right)}{\left(1-\bar{X} \cdot \overline{B_{2}}\right)^{2}+\bar{X}^{2}} \\
& \operatorname{Im}\left(\overline{Y_{\mathrm{L} 1}^{\prime}}\right)=\frac{\overline{B_{1}} \cdot\left(1-\bar{X} \cdot \overline{B_{2}}\right)-\bar{X}}{\left(1-\bar{X} \cdot \overline{B_{2}}\right)^{2}+\bar{X}^{2}}
\end{aligned}
$$

where $\bar{X}=j \cdot \omega \overline{L_{0}}, \overline{B_{1}}=j \cdot \omega \overline{C_{01}}, \overline{B_{2}}=j \cdot \omega \overline{C_{02}}$. By assuming a convenient value for $\mathrm{L}_{0}\left(\mathrm{~L}_{0}=3 \mathrm{nH}\right)$, the system in (2) can be solved for $\mathrm{C}_{01}$ and $\mathrm{C}_{02}$ obtaining $\mathrm{C}_{01}=1.38 \mathrm{pF}$ and $\mathrm{C}_{02}=0.58$ $\mathrm{pF}$. The matching network is implemented as shown in Fig. 3. $\mathrm{C}_{\mathrm{var} 1}$ and $\mathrm{C}_{\mathrm{var} 2}$ are MOS varactors that use the gate capacitance of a MOS transistor and their capacitance value can be controlled by applying a voltage at the gate of it $\left(\mathrm{V}_{\mathrm{ctl1}}, \mathrm{V}_{\mathrm{ct} 12}\right)$. Fixed capacitors, $\mathrm{C}_{\mathrm{P} 1}$ and $\mathrm{C}_{\mathrm{P} 2}$, must be connected in series before the variable capacitor in order to block the gate DC voltage, preventing it from going to the output of the PA. Another advantage of using two capacitors in series is that the peak voltage at the drain gets divided by two (approximately), hence minimizing the risk of breakdown. In this design the chosen values for $\mathrm{C}_{\mathrm{P} 1}, \mathrm{C}_{\mathrm{P} 2}$ are $10 \mathrm{pF}$ and $6.1 \mathrm{pF}$ respectively, and the varactor capacitance range is $1.1 \mathrm{pF}-2.4 \mathrm{pF}$ for $\mathrm{C}_{\mathrm{var}}$, and $0.54 \mathrm{pF}-1.1 \mathrm{pF}$ for $\mathrm{C}_{\mathrm{var} 2}$. These selections are justified by the simulations performed in Section II.C. As shown in the simulated results of Fig. 4 and Fig. 5, the selected varactor ranges are appropriate to cover a region in the Smith Chart of amplifier load impedances (antenna) with reflection coefficient magnitude up to 0.5 , which are transformed in a circle close to the optimal transistor load impedance at fundamental frequency (with PAE $>27 \%$ ). The particular varactor values $\mathrm{C}_{\mathrm{var} 1}=1.6 \mathrm{pF}$ and $\mathrm{C}_{\mathrm{var} 2}=0.64 \mathrm{pF}$, combined with $\mathrm{C}_{\mathrm{P} 1}$ and $\mathrm{C}_{\mathrm{P} 2}$, produce $\mathrm{C}_{01}=1.38 \mathrm{pF}$ and $\mathrm{C}_{02}=0.58 \mathrm{pF}$, as required in the nominal case of a $50 \Omega$ (antenna) load discussed above.

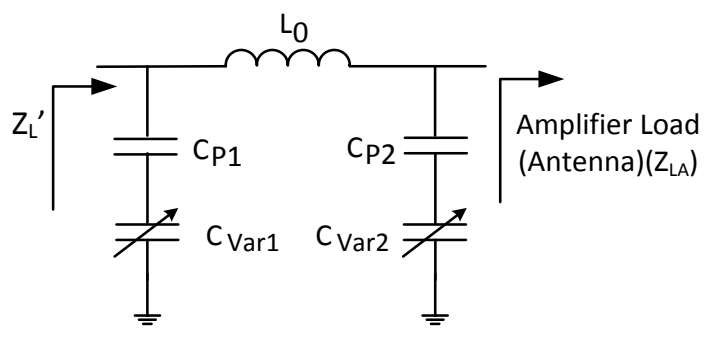

Fig. 3. Implementation of the matching network of Fig. 2(a) at fundamental frequency, using a series connection of capacitor and MOS varactor.

\section{Impedance reconfiguration}

The operation of the OMN to compensate the effect of load variation on the performance of the PA is demonstrated in Fig. 4 , in which the simulated OMN input impedances for the full range of varactor capacitances $\mathrm{C}_{\mathrm{var} 1}$ and $\mathrm{C}_{\mathrm{var} 2}$ are plotted on a 
Smith Chart at fundamental frequency, $2^{\text {nd }}$ and $3^{\text {rd }}$ harmonics. All the OMN circuit elements shown in Fig. 2, namely the CLC pi-network at fundamental (tuner), $\mathrm{L}_{2} \mathrm{C}_{2}$ resonator at $2^{\text {nd }}$ harmonic, $\mathrm{L}_{3} \mathrm{C}_{3}$ resonator at $3^{\text {rd }}$ harmonic, inductance $\mathrm{L}_{\mathrm{d}}$ and capacitance $\mathrm{C}_{\mathrm{s}}$ are included in the simulation. Therefore any effect caused by the harmonic circuit elements is taken into account at fundamental frequency, and also the effect of variation of capacitances $\mathrm{C}_{\mathrm{var} 1}$ and $\mathrm{C}_{\mathrm{var} 2}$ are included in the simulation at harmonic frequencies. Different amplifier load impedances with increasing reflection coefficient magnitude have been considered. As a first case Fig. 4(a)-(b) show the simulated OMN input impedance for a nominal load impedance $\left(\mathrm{Z}_{\mathrm{LA}}=50 \Omega\right)$. In Fig. $4(\mathrm{a})$ the $\mathrm{OMN}$ circuit elements are ideal (lossless). In Fig. 4(b) lossy elements are considered, with quality factors $\mathrm{Q}_{\mathrm{L}}=12$ for inductors and $\mathrm{Q}_{\mathrm{C}}$ $=20$ for capacitors (including MOS varactors), which are commonly used in CMOS technology.

From inspection of Fig. 4(a)-(b) the following conclusions of the OMN operation for nominal amplifier load impedance are extracted:

- The OMN input impedance range at fundamental frequency includes the optimal value $\left(Z_{L 1}=42+j 21.6\right.$ $\Omega$ ) from load-pull simulations. Specifically, this is achieved for $\mathrm{C}_{\mathrm{var} 1}=1.6 \mathrm{pF}$ and $\mathrm{C}_{\mathrm{var} 2}=0.64 \mathrm{pF}$, within the capacitance variation range. Moreover, as it can be observed comparing with the PAE contours of Fig. 1(a), most OMN input impedance values fall inside a circle featuring good amplifier performance with PAE > 27\% and $P_{\text {out }}>17 \mathrm{dBm}$. Therefore possible inaccuracies in setting the varactor voltages (thus capacitances) have a little impact in the amplifier performance.

- The OMN input impedance at $2^{\text {nd }}$ harmonic is independent of the varactor capacitance variation, and therefore the $2^{\text {nd }}$ harmonic is decoupled from tuning at fundamental frequency. Regarding the $3^{\text {rd }}$ harmonic, the imaginary part changes with varactor capacitance, though the variation range is small (from j49 $\Omega$ to $\mathrm{j} 63$ $\Omega$ ), with a negligible impact on PAE and output power as it can be observed in Fig. 1(c).

- Loss in the circuit elements (including MOS varactors) has a small effect in the input impedance distribution at fundamental frequency. In particular, comparing Fig. 4(a) to Fig. 4(b), a maximum phase rotation of $20^{\circ}$ and a reduction of 0.06 in the reflection coefficient magnitude are observed, but always keeping the optimal impedance value within the range of varactor capacitances. The effect of losses is more apparent on impedances at the $2^{\text {nd }}$ and $3^{\text {rd }}$ harmonic, featuring a reflection coefficient magnitude of 0.85 ( $2^{\text {nd }}$ harmonic $)$ and $0.69\left(3^{\text {rd }}\right.$ harmonic), but the PAE and output power are unaffected.

The OMN input impedance has been simulated for load impedances $Z_{\mathrm{LA}}$ with a reflection coefficient $\Gamma_{L A}=\left|\Gamma_{L A}\right| e^{j \phi_{L A}}$ of increasing magnitude $\left(0 \leq\left|\Gamma_{\mathrm{LA}}\right| \leq 0.5\right)$ and full phase range $\left(-180^{\circ} \leq \phi_{L A} \leq 180^{\circ}\right)$, simultaneously sweeping the varactor capacitances $\mathrm{C}_{\mathrm{var} 1}$ and $\mathrm{C}_{\mathrm{var} 2}$ in their full capacitance range. All

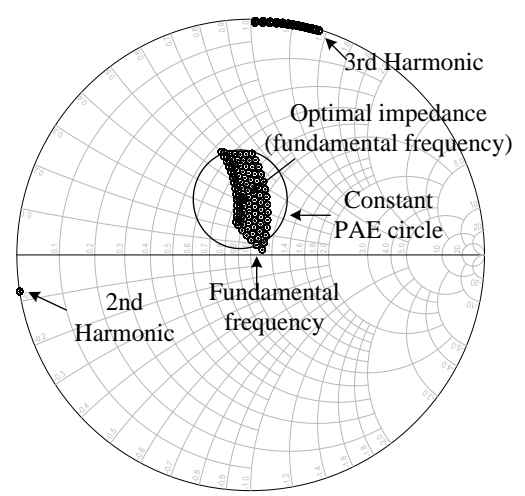

(a)

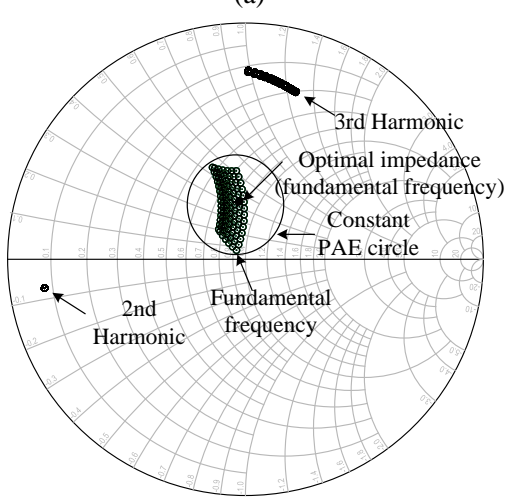

(b)

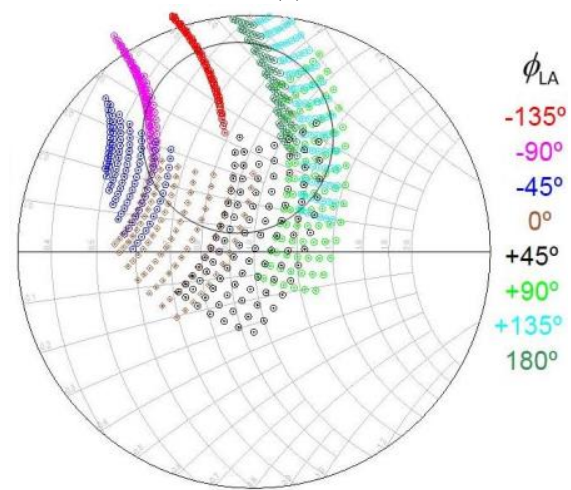

(c)

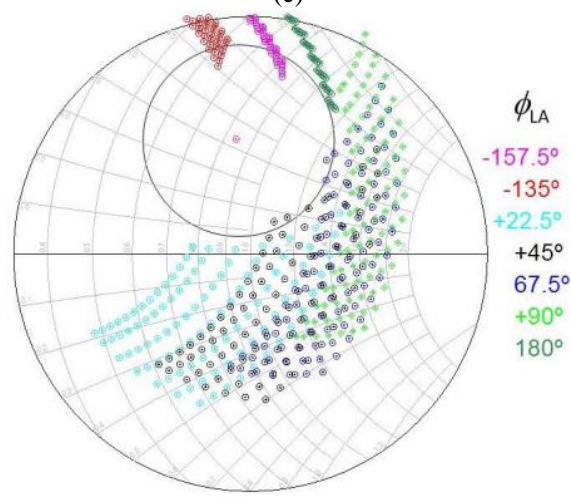

(d)

Fig. 4. Simulated OMN input impedance for different load impedances $Z_{\mathrm{LA}}$ and full range of varactor capacitance variation. (a) Ideal (lossless) OMN with $50 \Omega$ load. (b) Lossy OMN with $50 \Omega$ load. (c) Lossy OMN with $\left|\Gamma_{\mathrm{LA}}\right|=0.3$ and full phase variation $\left(-180^{\circ} \leq \phi_{L A} \leq 180^{\circ}\right)$. (d) Lossy OMN with $\left|\Gamma_{\mathrm{LA}}\right|=0.5$ and full phase variation $\left(-180^{\circ} \leq \phi_{L A} \leq 180^{\circ}\right)$. 
circuit elements are considered lossy, with same quality factor as in the previous $50 \Omega$ simulation. Fig. 4(c)-(d) show the results for the particular cases $\left|\Gamma_{\mathrm{LA}}\right|=0.3$ and $\left|\Gamma_{\mathrm{LA}}\right|=0.5$ and full range of phase $\phi_{L A}$ with an increment of $45^{\circ}$, in a zoomed Smith chart. Every simulated OMN input impedance set for a given phase $\phi_{L A}$ consists of a "matrix" of dots corresponding to the different $C_{\text {var1 }}$ and $C_{\text {var2 }}$ values. A constant PAE circle around the optimal OMN input impedance at fundamental frequency is also drawn, in order to assess which load impedances will be transformed into OMN input impedances yielding PAE $>27 \%$ and $P_{\text {out }}>17 \mathrm{dBm}$, which are only slightly smaller ( $3 \%$ and $0.5 \mathrm{~dB}$, respectively) than the optimal results. It can be observed that any impedance $\mathrm{Z}_{\mathrm{LA}}$ with $\left|\Gamma_{\mathrm{LA}}\right| \leq$ 0.3 is transformed within the $27 \%$ PAE circle for some value of the varactor capacitances. Impedances with $0.3 \leq\left|\Gamma_{\mathrm{LA}}\right| \leq 0.5$ are also transformed within the circle but with limited phase range. In the limit $\left(\left|\Gamma_{\mathrm{LA}}\right|=0.5\right)$, the allowed phase range is $-180^{\circ} \leq \phi_{\mathrm{LA}} \leq-125^{\circ}$ and $33^{\circ} \leq \phi_{\mathrm{LA}} \leq 75^{\circ}$. Higher reflection coefficient values $\left(\left|\Gamma_{\mathrm{LA}}\right|>0.5\right)$ are transformed outside, but surrounding the circle. Therefore though the theoretical PAE and output power will be smaller than $27 \%$ and $17 \mathrm{dBm}$, respectively, the OMN will still be compensating the varying load impedance to achieve the best possible amplifier performance. The $2^{\text {nd }}$ and $3^{\text {rd }}$ harmonic impedances are insensitive to load impedance variations. Although not shown in the zoomed view of Fig. 4(c)-(d), the harmonic impedances follow the same pattern as in Fig. 4(a)-(b). The black area in Fig. 5(a) depicts the load impedance region that will be transformed within the constant PAE circle, which agrees with the perturbed region for mobile phones reported in the literature [22], [23]. The necessary capacitances $C_{\text {var1 }}$ and $C_{\text {var2 }}$ to cover this area can then be mapped into varactor actuation voltages, $\mathrm{V}_{\text {ctl1 }}$ and $\mathrm{V}_{\text {ctl2 }}$, respectively, which range is $-3.3 \mathrm{~V}$ to $+3.3 \mathrm{~V}$. Fig. 5 (b) shows the varactor actuation voltages as a function of the load reflection coefficient magnitude $\left(\left|\Gamma_{\mathrm{LA}}\right|\right)$ and phase $\left(\phi_{L A}\right)$. It can be observed that the required control voltages mainly depend on the phase.

\section{Power Amplifier Implementation}

Using the reconfigurable output matching structure proposed in Section II.B, the final reconfigurable CMOS class-F PA configuration is shown in Fig. 6. A cascode structure has been selected that permits higher bias voltages without damaging the transistors. The input matching network is composed of a series inductor $\mathrm{L}_{\mathrm{i}}\left(\mathrm{L}_{\mathrm{i}}=4.6 \mathrm{nH}\right)$ and a parallel capacitor $\mathrm{C}_{\mathrm{i}}\left(\mathrm{C}_{\mathrm{i}}=0.61 \mathrm{pF}\right)$ to match the power device to $50 \Omega$ input impedance for a high power transfer. MOS varactors in the OMN and inductors are critical in terms of loss. In Section III the PA performance degradation due to these losses is simulated and compared to measurements. A picture of the fabricated chip is shown in Fig. 7 in which the pads for RF signal, and CMOS transistor and MOS varactor DC-bias are apparent.

\section{Simulation And Measurement Results}

Simulations are performed with Keysight ADS and
Cadence Spectre RF software packages considering the circuit of Fig. 6. The nominal bias point is $\mathrm{V}_{\mathrm{DD}}=3 \mathrm{~V}, \mathrm{~V}_{\mathrm{GG}}=1.3 \mathrm{~V}$, with DC drain current ranging from $44 \mathrm{~mA}$ to $63 \mathrm{~mA}$ for input powers from $-10 \mathrm{dBm}$ to $+15 \mathrm{dBm}$, respectively.

\section{A. $50 \Omega$ load}

In a first case a nominal load (antenna) impedance $\mathrm{Z}_{\mathrm{LA}}=50$ $\Omega$ (impedance $\mathrm{Z}_{\mathrm{LA} 0}$ at the center of Smith Chart in Fig. 5(a)) is considered and the MOS varactors are fixed to their nominal values $\mathrm{C}_{\mathrm{var} 1}=1.6 \mathrm{pF}$ and $\mathrm{C}_{\mathrm{var} 2}=0.64 \mathrm{pF}$. Fig. 8 compares the simulated $P_{\text {out }}$ and PAE vs. $P_{\text {in }}$ under three assumptions: (i) ideal (lossless) elements in matching networks; (ii) lossy inductors but ideal capacitors; (iii) lossy inductors and lossy capacitors (including MOS varactors). In cases (ii) and (iii)

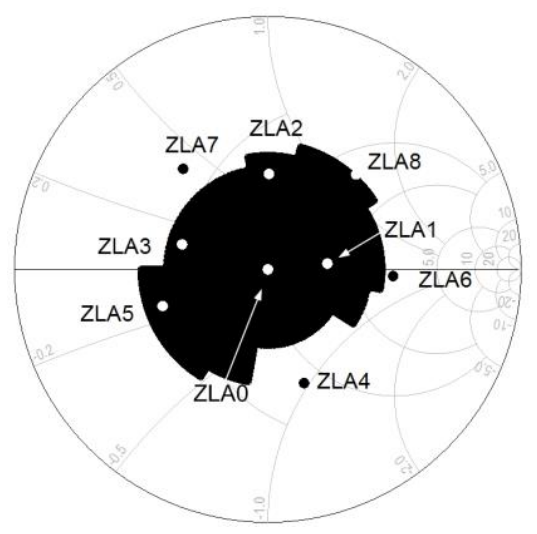

(a)
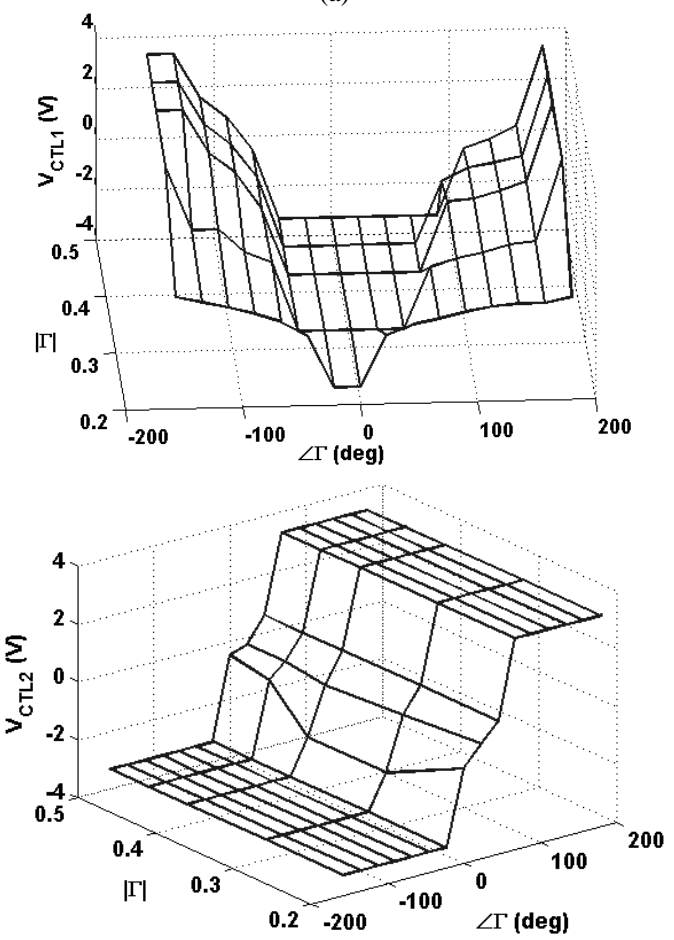

(b)

Fig. 5. (a) Load impedance region (black marked area) which is transformed within a circle of PAE $=27 \%$. Superimposed white and black dots are the load impedances used in PA experimental characterization in Section III: one matched $(50 \Omega$ ) load (white dot in the center of the Smith Chart) and eight mismatched loads $\mathrm{Z}_{\mathrm{LA} 1}$ to $\mathrm{Z}_{\mathrm{LA} 8}$ listed in Table II). (b) Varactor actuation voltages as a function of the load reflection coefficient phase $\phi_{L A}$ and magnitude $\left|\Gamma_{\mathrm{LA}}\right|$. 


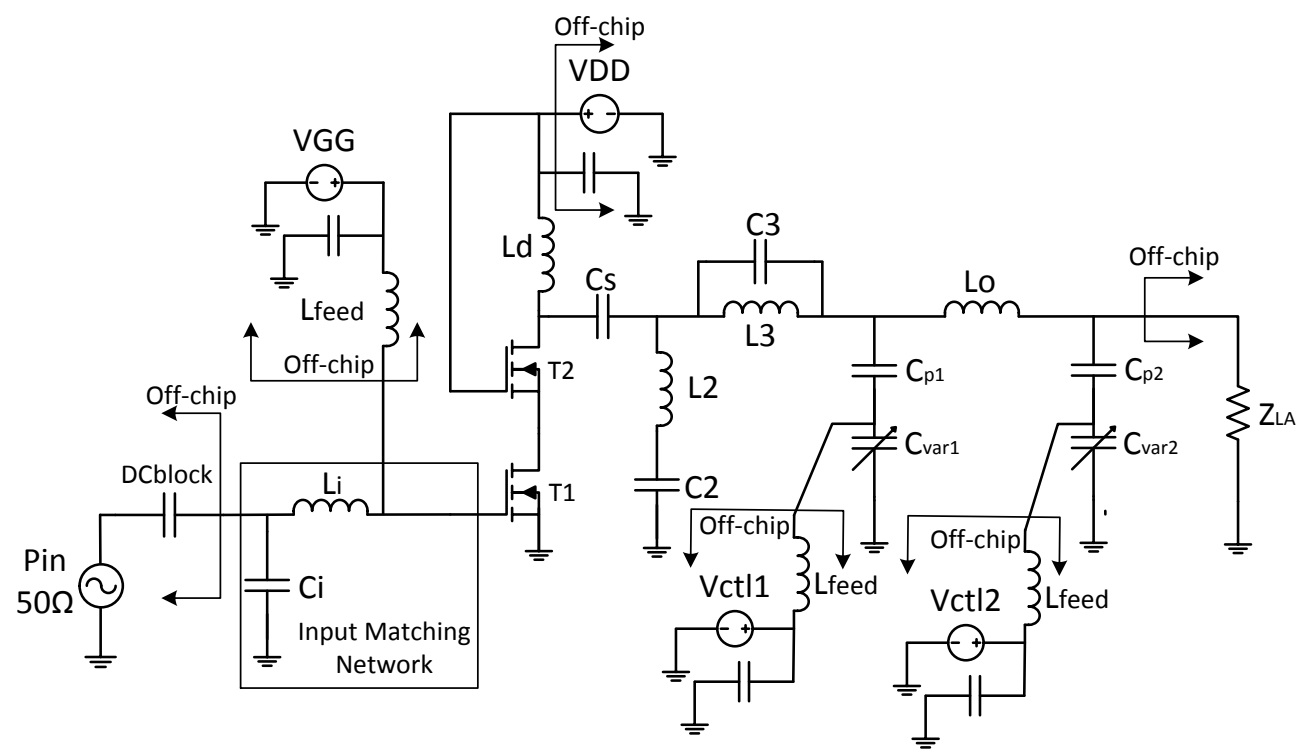

Fig. 6. Proposed reconfigurable class-F PA.

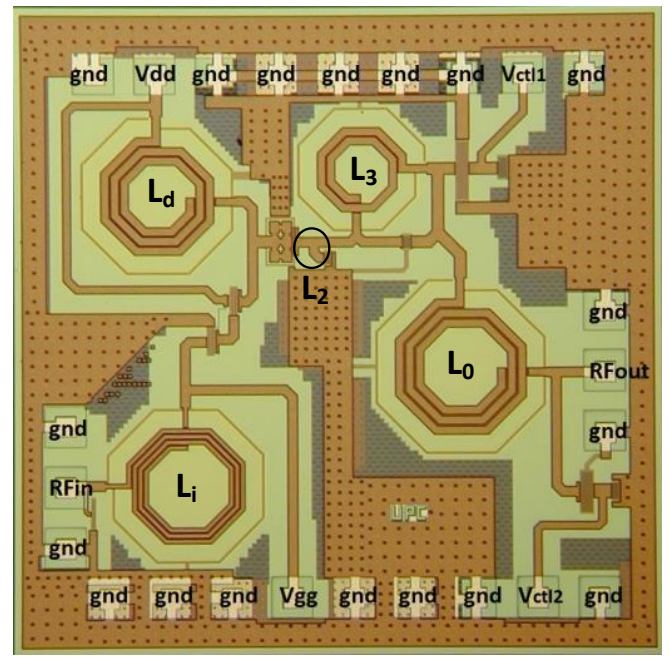

Fig. 7: Fabricated PA chip in TSMC ${ }^{\mathrm{TM}} 0.18 \mu \mathrm{m}$ CMOS technology. Die size is $1.6 \mathrm{~mm} \times 1.6 \mathrm{~mm}$.

complex foundry models which take into account loss and couplings are used for the inductors and capacitors. The maximum $P_{\text {out }}$ is $21.1 \mathrm{dBm}, 19.4 \mathrm{dBm}$ and $18.7 \mathrm{dBm}$ and the optimal PAE is $57 \%, 34 \%$ and $28.9 \%$, for cases (i), (ii) and (iii), respectively. These results agree with the predictions from load-pull analysis in Fig. 1(a). In case (iii) the $-1 \mathrm{~dB}$ compression point is $P_{\text {out_ldB }}=14.5 \mathrm{dBm}$, and for optimal PAE, $G_{\mathrm{p}}=10.2 \mathrm{~dB}, P_{\mathrm{in}}=8 \mathrm{dBm}$. It can be observed that the inductor loss is a main limitation for $P_{\text {out }}$ and PAE, whereas loss associated to capacitors has a smaller contribution. The simulated drain voltage and current waveforms of the PA for different input powers are shown in Fig. 9. It can be observed that in order to achieve a proper class- $F$ voltage and current waveforms, a high input drive bigger than $2 \mathrm{dBm}$ is required.

Using a measurement setup consisting in a wafer-probe station connected to a network analyzer, the results of Figs. 10 to 12 have been obtained. Fig. 10 compares the measured and simulated large signal S-parameters of the fabricated PA chip, showing a good agreement. For an input power of $5 \mathrm{dBm}$ the

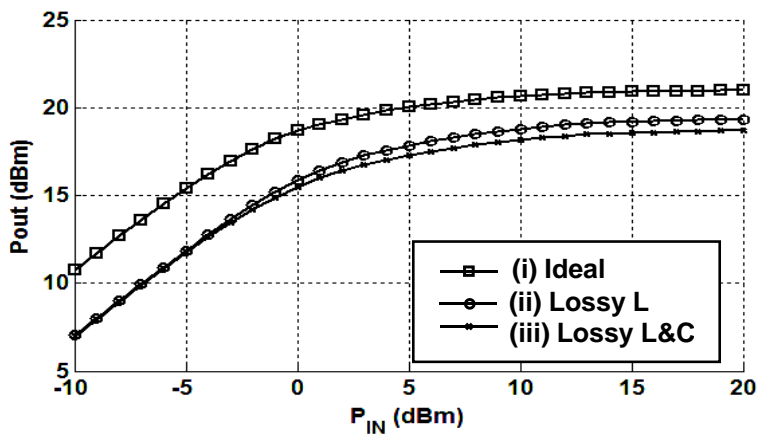

(a)

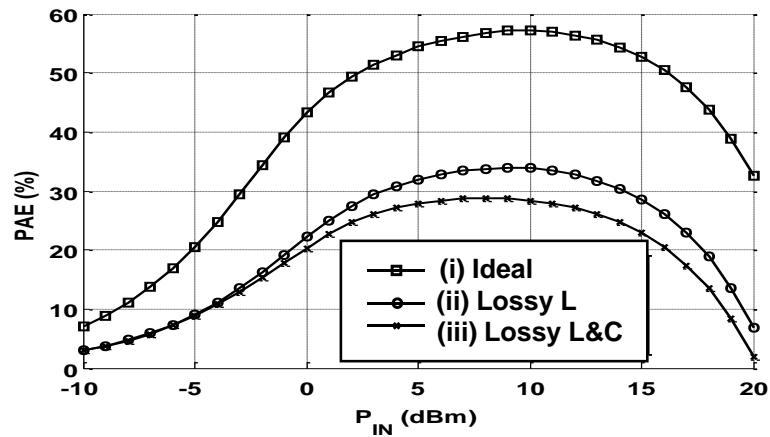

(b)

Fig. 8. Simulated PA behavior for $V_{D D}=3 V$. (a) Output power. (b) PAE.

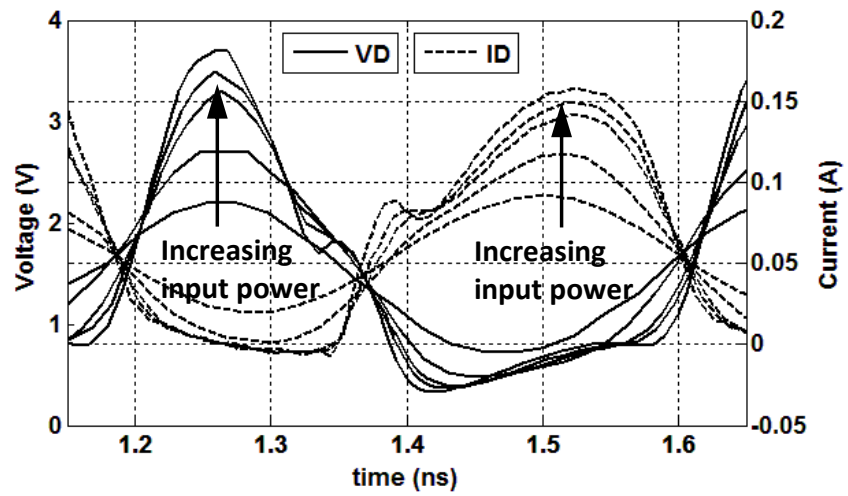

Fig. 9. Simulated drain voltage and current waveforms of the proposed class-F PA for different input powers $(-5 \mathrm{dBm}, 0 \mathrm{dBm}, 5 \mathrm{dBm}, 7 \mathrm{dBm}, 10 \mathrm{dBm})$. 


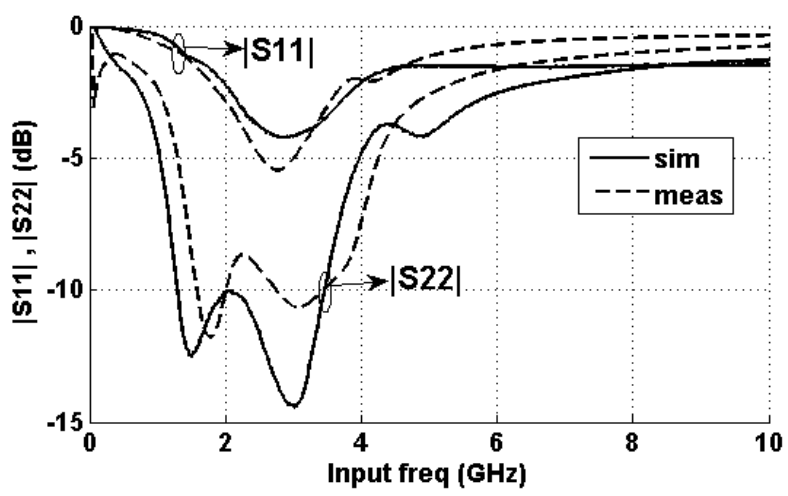

(a)

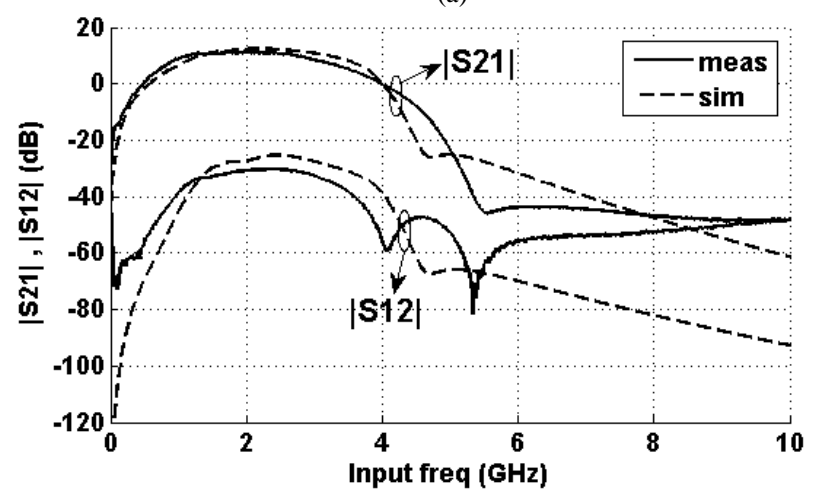

(b)

Fig. 10. Simulated (dash) and measured (solid) large signal S-parameter results of the proposed class-F PA: (a) $\left|S_{11}\right|$ and $\left|S_{22}\right|$, (b) $\left|S_{21}\right|$ and $\left|S_{12}\right|$.

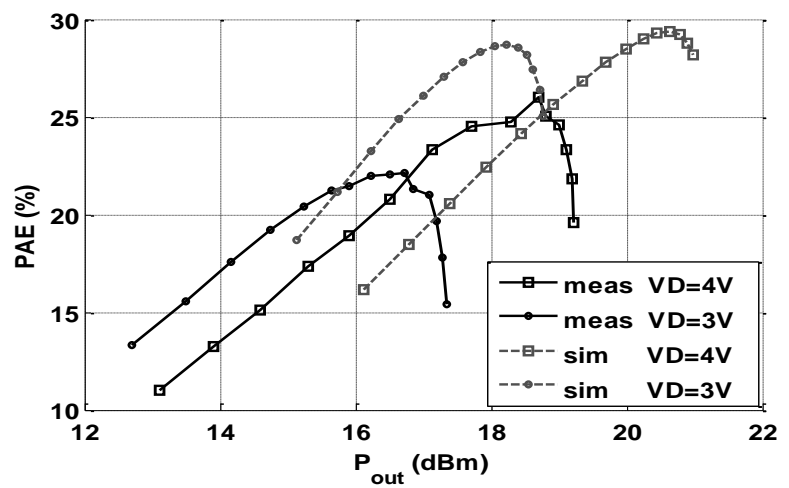

Fig. 11. Simulated and measured PAE (\%) as a function of output power for bias voltages $\mathrm{V}_{\mathrm{DD}}=3 \mathrm{~V}$ and $\mathrm{V}_{\mathrm{DD}}=4 \mathrm{~V}$.

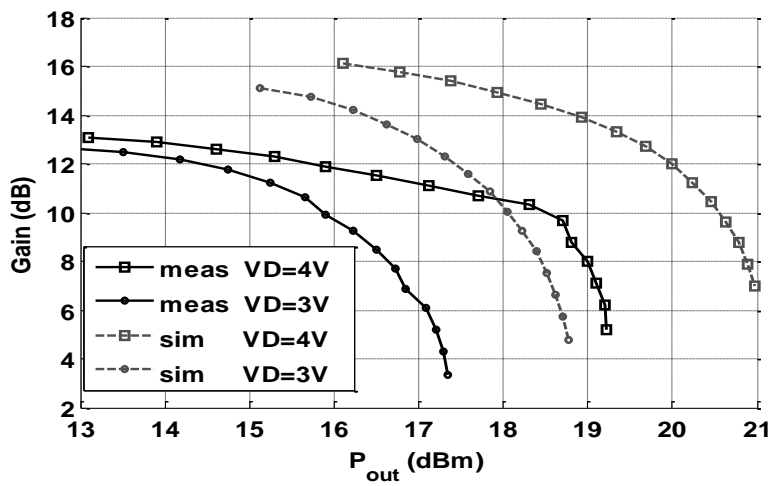

Fig. 12. Simulated and measured gain $(\mathrm{dB})$ as a function of output power for bias voltages $\mathrm{V}_{\mathrm{DD}}=3 \mathrm{~V}$ and $\mathrm{V}_{\mathrm{DD}}=4 \mathrm{~V}$.

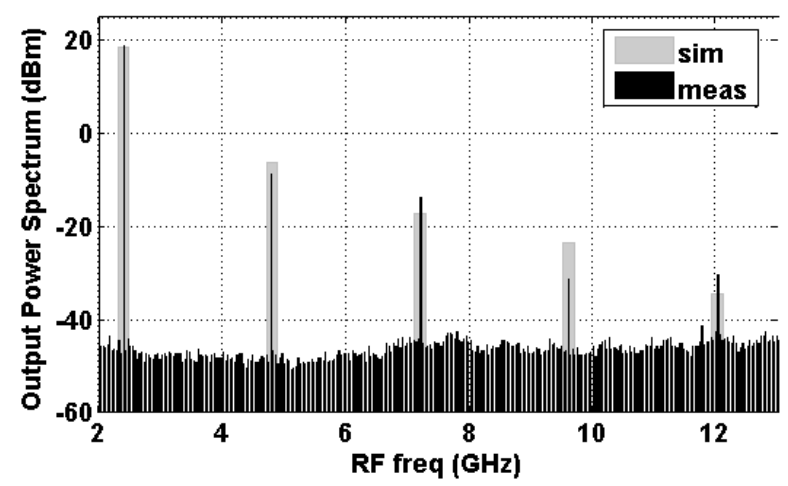

Fig. 13. Simulated (grey) and measured (black) output power spectrum for 50 $\Omega$ load impedance.

measured gain is $11.5 \mathrm{~dB}$ and the simulated gain is $12.3 \mathrm{~dB}$ at 2.4 GHz. The PA performance regarding PAE and $G_{\mathrm{p}}$ are measured versus output power and compared to simulations in Fig. 11 and Fig. 12. Besides the nominal bias point a higher bias voltage $\left(\mathrm{V}_{\mathrm{DD}}=4 \mathrm{~V}, \mathrm{~V}_{\mathrm{GG}}=1.5 \mathrm{~V}\right)$ has also been used in measurements. For $\mathrm{V}_{\mathrm{DD}}=3 \mathrm{~V}$, a maximum measured PAE of $22 \%$ for $P_{\text {out }}=16.8 \mathrm{dBm}$ with $G_{\mathrm{p}}=7.9 \mathrm{~dB}$ is obtained. For $\mathrm{V}_{\mathrm{DD}}=4 \mathrm{~V}$, the maximum measured PAE increases to $26.5 \%$ for $P_{\text {out }}=18.7 \mathrm{dBm}$ with $G_{\mathrm{p}}=9.7 \mathrm{~dB}$, and a maximum output power of $19.2 \mathrm{dBm}$ is obtained with a PAE of $20 \%$, being the measured $-1 \mathrm{~dB}$ compression point $P_{\text {out_ldB }}=15.8 \mathrm{dBm}$. The measured OIP3 and IIP3 are $23.4 \mathrm{dBm}$ and $12.2 \mathrm{dBm}$, respectively. In both cases the measured output power is shifted down $2 \mathrm{~dB}$ with respect to the simulated output power. This difference is mainly attributed to the quality factor of fabricated inductors and capacitors (including MOS varactors) which may have been overestimated in simulation. If, for instance, slightly smaller values $\left(\mathrm{Q}_{\mathrm{L}}=8\right.$ and $\left.\mathrm{Q}_{\mathrm{C}}=15\right)$ were considered, then $G_{\mathrm{p}}$ decreases by $1.5 \mathrm{~dB}$.

For nonlinear measurements a CW/digitally-modulated RF generator is connected to the input of the wafer-probe station and a spectrum analyzer/vector signal analyzer to its output. A directional coupler is inserted between the wafer-probe station output and the spectrum analyzer in order to obtain an accurate measurement of the output power using its coupled port. To this end, the loss produced by the directional coupler and connection cable is characterized prior to the measurement. The simulation and measurement results of the output spectrum are shown in Fig. 13. The measured harmonic rejection for $2^{\text {nd }}$ and $3^{\text {rd }}$ harmonics are $28 \mathrm{dBc}$ and $32.6 \mathrm{dBc}$ respectively. The output spectrum shows a high harmonic suppression up to $5^{\text {th }}$ harmonic which shows that the proposed topology has the ability to reject harmonics without an extra filtering section. The measured total harmonic distortion (THD) is $4.9 \%$.

To assess the PA nonlinear behavior under real operating conditions, adjacent-channel leakage ratio (ACLR) measurements have been performed using IEEE $802.11 \mathrm{~g} \mathrm{WiFi}$ signals (OFDM-64 QAM with maximum data rate of $54 \mathrm{Mb} / \mathrm{s}$ and PAPR $=9 \mathrm{~dB}$ ) delivered to the PA input. Fig. 14 shows the measured spectrum regrowth at the output of the amplifier for $P_{\text {out }}=+2 \mathrm{dBm}$ and $P_{\text {out }}=+18.7 \mathrm{dBm}$. The latter 
corresponds to maximum PAE. The bias condition is $\mathrm{V}_{\mathrm{DD}}=4$ $\mathrm{V}$. It can be observed that the PA meets $\mathrm{WiFi}$ mask specifications (trace below blue limit line) for $P_{\text {out }} \leq 18 \mathrm{dBm}$. The measured ACLR values (in $\mathrm{dBc}$ ) at $2.412 \mathrm{GHz}$ (WiFi channel \#1) for different output powers are presented in Table I. As expected, ACLR degrades with increasing $\mathrm{P}_{\text {out }}$, but even at highest $\mathrm{P}_{\text {out }}$ levels (with optimum PAE) ACLR is better than $-26.6 \mathrm{dBc}$. Fig. 15 shows the measured EVM (\%) of a WiFi IEEE 802.11g OFDM-64 QAM signal with maximum data rate of $54 \mathrm{Mb} / \mathrm{s}$. For $P_{\text {out }} \leq 7 \mathrm{dBm}$ the PA features an EVM $\leq$ $1.3 \%$. For $P_{\text {out }} \leq 13 \mathrm{dBm}$ the PA features an EVM $\leq 5.6 \%$, which allows the maximum specified data rate $(54 \mathrm{Mb} / \mathrm{s})$. For $P_{\text {out }}=18 \mathrm{dBm}$, the EVM is $14.4 \%$, which allows a maximum data rate of $24 \mathrm{Mb} / \mathrm{s}$. The above results mean the PA must operate at $5.7 \mathrm{~dB}$ back-off to meet the EVM specifications at maximum data rate $(54 \mathrm{Mb} / \mathrm{s})$. Back-off is evaluated as the maximum output power for maximum PAE $(18.7 \mathrm{dBm})$ minus the output power to meet the EVM specifications $(13 \mathrm{dBm})$.
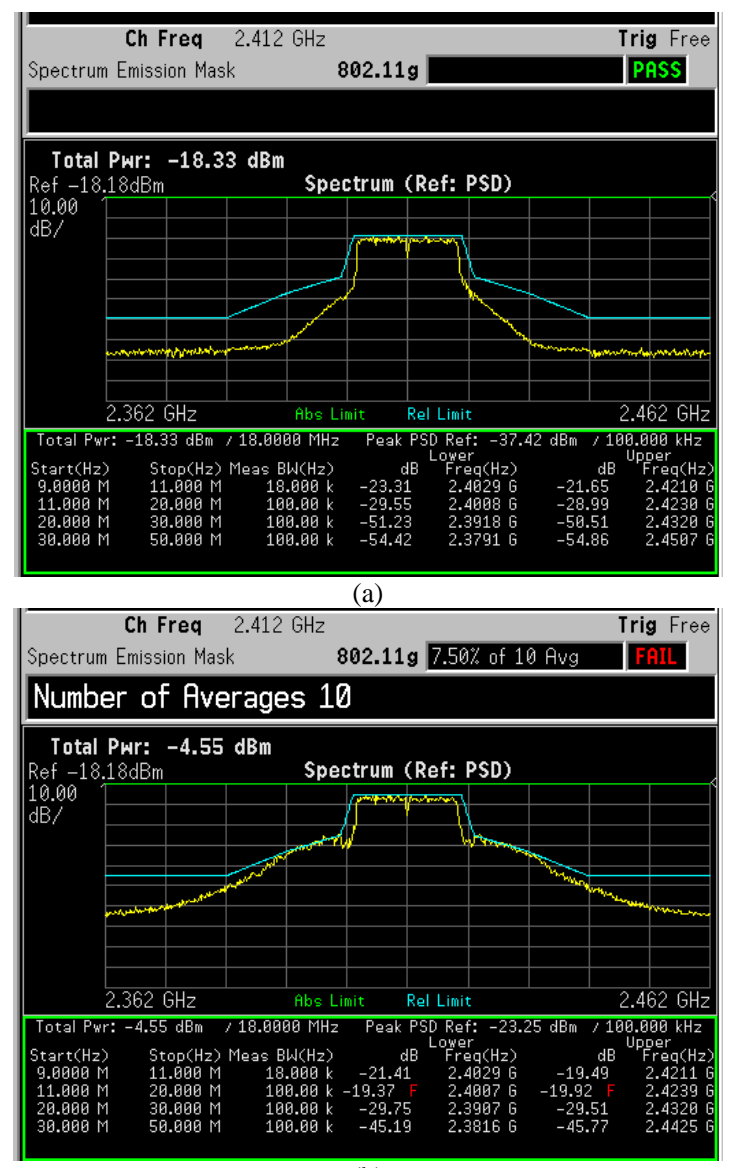

(b)

Fig. 14. Measured spectrum regrowth of a WiFi IEEE $802.11 \mathrm{~g}$ signal produced by the PA with a matched $50 \Omega$ load. (a) $P_{\text {out }}=+2 \mathrm{dBm}$. (b) $P_{\text {out }}=$ $+18.7 \mathrm{dBm}$ (corresponding to maximum PAE). The indicated absolute power levels are not actual PA output power because of the measurement setup couplers and attenuators.

\section{B. Mismatched loads}

In order to test the effect of antenna load $\left(\mathrm{Z}_{\mathrm{LA}}\right)$ variation, which can occur by the hand and head effect on the mobile phone [22], [23], the PA is measured with different mismatched loads and tuned. Using an output tuner, eight load impedances covering the theoretical load impedance region (black region in Fig. 5(a)), which is transformed within a circle of $\mathrm{PAE}=27 \%$, have been synthesized at $2.4 \mathrm{GHz}$. The tuner is composed of a $50 \Omega$ coaxial sliding line to change the load (antenna) reflection coefficient phase, and a $25 \Omega$ fixed line which can be combined with a fixed attenuator to change the load (antenna) reflection coefficient magnitude. The tuner is inserted between the power amplifier output and the network analyzer (or spectrum analyzer/vector signal analyzer). These mismatched impedances are plotted as superimposed black and white dots in Fig. 5(a) $\left(\mathrm{Z}_{\mathrm{LA} 1}\right.$ to $\left.\mathrm{Z}_{\mathrm{LA} 8}\right)$ and listed in Table II.

TABLE I

MEASURED ACLR FOR DIFFERENT LOAD IMPEDANCES AND OUTPUT POWERS

\begin{tabular}{ccccccc}
\hline \hline & \multicolumn{2}{c}{$P_{\text {out }}=12 \mathrm{dBm}$} & \multicolumn{2}{c}{$P_{\text {out }}=16 \mathrm{dBm}$} & \multicolumn{3}{c}{$\begin{array}{c}P_{\text {out }}=18 \mathrm{dBm} \\
\text { (highest PAE) }\end{array}$} \\
\cline { 2 - 7 } $\begin{array}{c}\text { Load } \\
\text { impedance }(\Omega)\end{array}$ & $\begin{array}{c}\text { Not } \\
\text { tuned }\end{array}$ & Tuned & $\begin{array}{c}\text { Not } \\
\text { tuned }\end{array}$ & Tuned & $\begin{array}{c}\text { Not } \\
\text { tuned }\end{array}$ & Tuned \\
\hline $50^{*}(\mathrm{~L})$ & & -38.2 & & -30.3 & & -26.6 \\
$50^{*}(\mathrm{U})$ & & -39.9 & & -31.4 & & -26.9 \\
$19.9-\mathrm{j} 7.1(\mathrm{~L})$ & -35 & -38.4 & -26.3 & -29.7 & -23.3 & -26.4 \\
$19.9-\mathrm{j} 7.1(\mathrm{U})$ & -39.7 & -43.1 & -31.2 & -35 & -25 & -26.9 \\
$145.5-\mathrm{j} 18.5(\mathrm{~L})$ & -37.8 & -42.4 & -28.3 & -33 & -25 & -29.8 \\
$145.5-\mathrm{j} 18.5(\mathrm{U})$ & -38.3 & -42 & -29.9 & -33.5 & -25.5 & -29.3 \\
\hline \hline
\end{tabular}

* For a matched load $(50 \Omega), \mathrm{C}_{\mathrm{var} 1}$ and $\mathrm{C}_{\mathrm{var} 2}$ have nominal values

L: lower channel. U: upper channel.

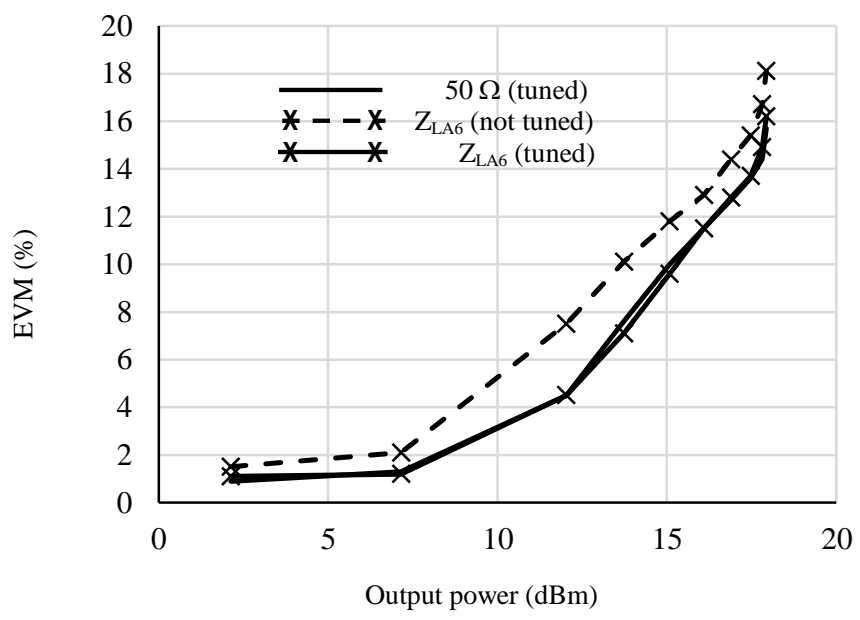

Fig. 15. Measured EVM (\%) of a WiFi IEEE $802.11 \mathrm{~g}$ signal produced by the PA with a matched $50 \Omega$ (antenna) load (in a tuned case), and with a mismatched (antenna) load $Z_{\mathrm{LA} 6}=145.5-\mathrm{j} 18.5 \Omega$ (not-tuned and tuned cases).

TABLE II

MEASURED PAE AND OUTPUT POWER FOR DIFFERENT LOAD IMPEDANCES

\begin{tabular}{ccccccc}
\hline \hline $\begin{array}{c}Z_{\mathrm{LA}_{\mathrm{i}} \mathrm{i}}(\Omega), \\
(\mathrm{i}=0,1, \ldots 8)\end{array}$ & \multicolumn{2}{c}{ Not Tuned } & \multicolumn{2}{c}{ Tuned var1 } & \multicolumn{2}{c}{ Tuned } \\
var1 and var2
\end{tabular}

* For a matched load $(50 \Omega), \mathrm{C}_{\mathrm{var} 1}$ and $\mathrm{C}_{\mathrm{var} 2}$ have nominal values

The PA is first measured for each load impedance, without 
applying any voltage to the MOS varactors $\left(\mathrm{C}_{\mathrm{var} 1}\right.$ and $\mathrm{C}_{\mathrm{var} 2}$ in Fig. 6). This case is referred as not-tuned performance. Then the MOS varactors are tuned manually by changing the DC voltage applied to their gate using the control voltages in the look-up table presented in Fig. 5(b) ranging from $-3 \mathrm{~V}$ to $3 \mathrm{~V}$. This case is referred to as tuned performance. Three tuning conditions are considered: not-tuned, tuned using only $\mathrm{C}_{\mathrm{var}}$ and tuned using both $\mathrm{C}_{\mathrm{var} 1}$ and $\mathrm{C}_{\mathrm{var} 2}$. The performance of the PA regarding measured PAE and gain for four selected loads are shown in Fig. 16 and Fig. 17 respectively.

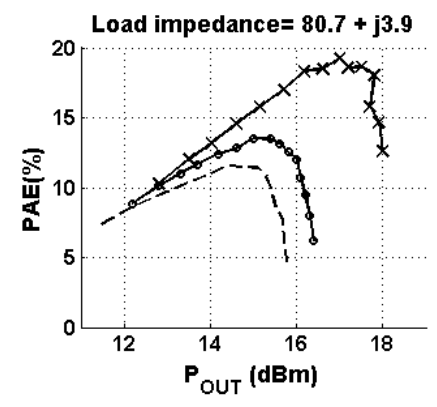

(a)

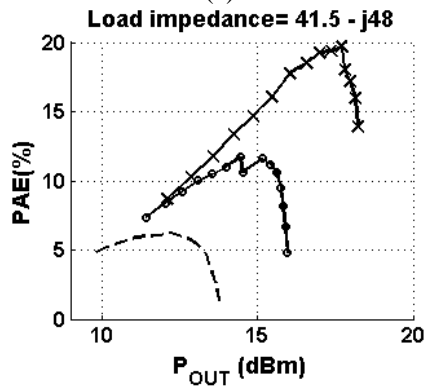

(c)

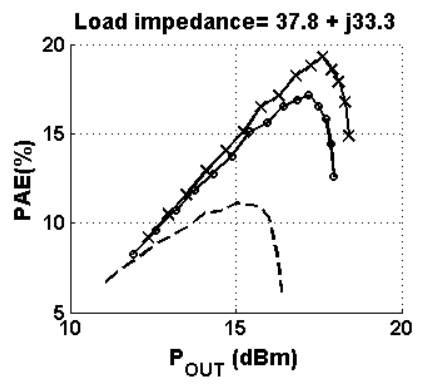

(b)

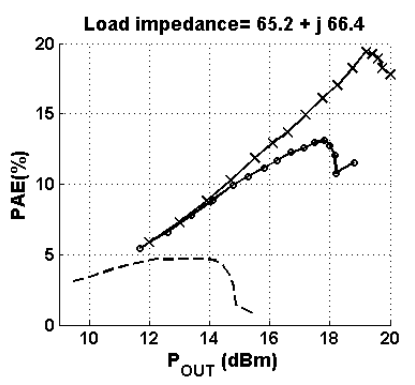

(d)
Fig. 16: Measured PAE for different load impedances of (a) $80.7+\mathrm{j} 3.9 \Omega$, (b) $37.8+\mathrm{j} 33.3 \Omega$, (c) $41.5-\mathrm{j} 48 \Omega$, and (d) $65.2+\mathrm{j} 66.4 \Omega$, compared in three different conditions of no tuning (dashed), one varactor (Var1) tuned (circle), and both varactors (Var1 and Var2) tuned (cross).

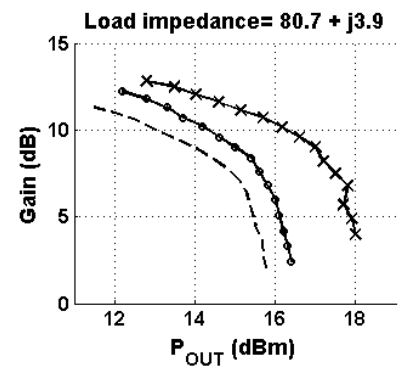

(a)

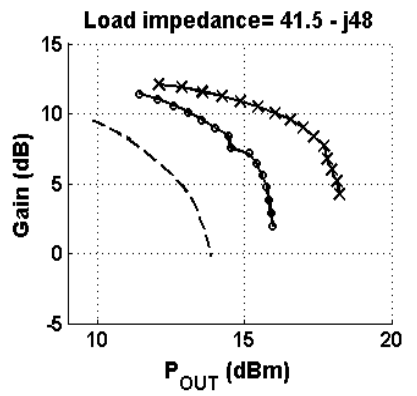

(c)

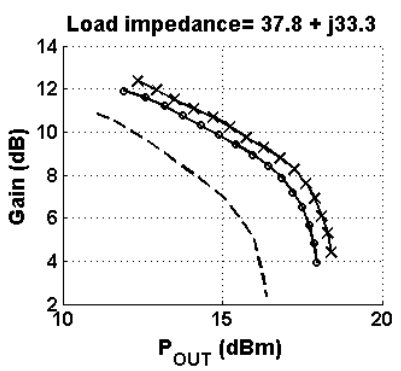

(b)

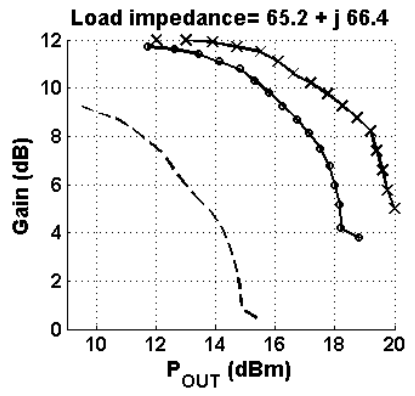

(d)
Fig. 17: Measured gain for the same impedances as in Fig. 16 compared in three different conditions of no tuning (dashed), one varactor (Var1) tuned (circle), and both varactors (Var1 and Var2) tuned (cross).

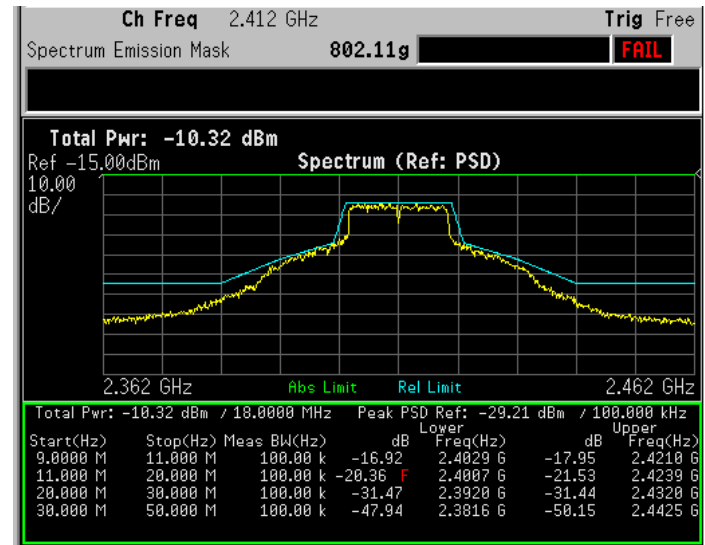

(a)

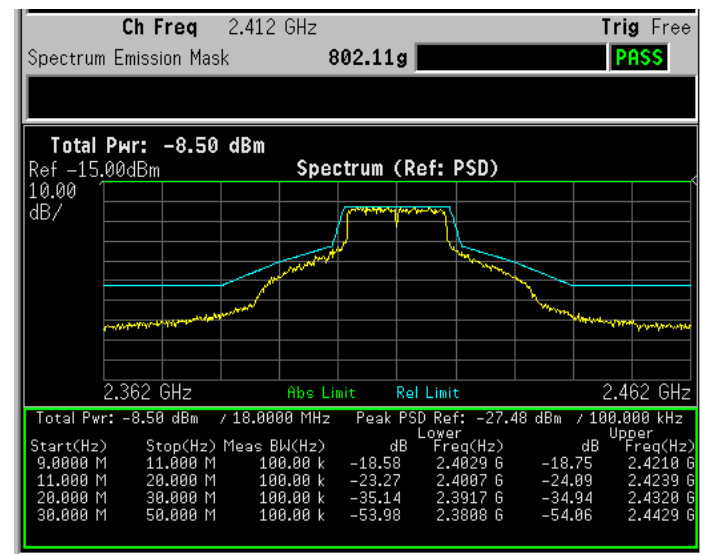

(b)

Fig. 18. Measured spectrum regrowth of a WiFi IEEE $802.11 \mathrm{~g}$ signal produced by the PA for the mismatched load $Z_{\mathrm{L} 65}=145.5-\mathrm{j} 18.5 \Omega$. (a) Nottuned state. (b) Tuned state with $P_{\text {out }}=16 \mathrm{dBm}$. The indicated absolute power levels are not actual PA output power because of the measurement setup couplers and attenuators.

It can be observed that when using $\mathrm{C}_{\mathrm{var} 1}$ as tuning element the gain and output power increase around 1-2 $\mathrm{dB}$, and when using both $\mathrm{C}_{\mathrm{var} 1}$ and $\mathrm{C}_{\mathrm{var} 2}$ as tuning elements a total gain and output power increase of $2 \mathrm{~dB}$ to $6 \mathrm{~dB}$ is achieved. In Fig. 17 it is observed that the gain for maximum PAE ranges from 8 to $9 \mathrm{~dB}$, very close to the matched load case. The tuning results are also compared in Table II showing, for each loadimpedance, a significant increase in PAE in the tuned condition with respect to not-tuned. For $Z_{\mathrm{LA} 1,} Z_{\mathrm{LA} 2,} Z_{\mathrm{LA} 4}, Z_{\mathrm{LA} 6}$ and $Z_{\mathrm{LA} 8}$, the tuned PAE is close to $19 \%$, in contrast to very low values for not-tuned condition. The highest tuned PAE is $19.9 \%$ for $Z_{\mathrm{LA} 6}$, and the highest $\mathrm{P}_{\text {out }}$ is $19.2 \mathrm{dBm}$ for $Z_{\mathrm{LA} 8}$, same as in the matched load condition. $Z_{\mathrm{LA} 4}=41.5-\mathrm{j} 48 \Omega$, which is theoretically out of the load impedance region of Fig. 5(a), reaches a tuned PAE of $19.7 \%$. This shows that the proposed circuit successfully compensates the effect of PA load variation. By tuning $\mathrm{C}_{\mathrm{var} 1}$ and $\mathrm{C}_{\mathrm{var} 2}$ varactors the nonlinear distortion is reduced with respect to not-tuned condition. As an example, Fig. 18 shows the measured spectrum regrowth for the mismatched load $Z_{\mathrm{LA} 6}=145.5-$ $\mathrm{j} 18.5 \Omega$ before and after tuning. In the tuned state, the PA is delivering an output power $P_{\text {out }}=16 \mathrm{dBm}$. It can be observed that in tuned condition the spectrum regrowth is highly 
TABLE III

COMPARISON WITH OTHER SWITCHED-MODE CMOS POWER AMPLIFIERS

\begin{tabular}{|c|c|c|c|c|c|c|c|c|c|c|c|c|}
\hline Ref. & $\begin{array}{l}\text { Techno } \\
\text { logy }\end{array}$ & $\begin{array}{l}\begin{array}{l}\text { Freq } \\
(\mathrm{GHz})\end{array} \\
\end{array}$ & Signal type & $\begin{array}{l}\mathrm{V}_{\mathrm{DD}} \\
(\mathrm{V})\end{array}$ & $\begin{array}{l}P_{\text {o max }} \\
(\mathrm{dBm})\end{array}$ & $\begin{array}{l}\text { PAE }_{\max } \\
(\%)\end{array}$ & $\begin{array}{l}\text { Gain }_{\max } \\
(\mathrm{dB})\end{array}$ & Distortion & $\begin{array}{l}\text { Area, } \\
\mathrm{mm}^{2}\end{array}$ & Class & $\begin{array}{l}\text { Reconfigu- } \\
\text { ration }\end{array}$ & Notes \\
\hline [5] & $\begin{array}{l}0.18 \mu \mathrm{m} \\
\text { CMOS }\end{array}$ & 5 & $\begin{array}{l}\text { Constant } \\
\text { envelope }\end{array}$ & 2 & 15.4 & 40.6 & NA & N/A & 0.81 & $\mathrm{E}$ & $\mathrm{NO}$ & $\begin{array}{l}\text { Fully Integrated } \\
\text { Injection-locking to } \\
\text { increase PAE }\end{array}$ \\
\hline [6] & $\begin{array}{l}90 \mathrm{~nm} \\
\text { CMOS }\end{array}$ & 1.8 & $\begin{array}{l}\text { Constant } \\
\text { envelope }\end{array}$ & $\begin{array}{l}2.5- \\
1.5\end{array}$ & 24 & 12 & NA & N/A & 3.69 & $\mathrm{E}$ & $\begin{array}{l}\text { Switched } \\
\text { capacitor } \\
\text { bank OMN }\end{array}$ & $\begin{array}{l}\text { Fully Integrated } \\
\text { Tuning for DC supply } \\
\text { compensation }\end{array}$ \\
\hline [4] & $\begin{array}{l}0.18 \mu \mathrm{m} \\
\mathrm{CMOS}\end{array}$ & 2.4 & $\begin{array}{l}\text { Constant } \\
\text { envelope }\end{array}$ & 0.8 & 9 & NA & 19 & N/A & 0.7 & $\mathrm{E}$ & NO & Fully Integrated \\
\hline [19] & $\begin{array}{l}0.18 \mu \mathrm{m} \\
\text { CMOS }\end{array}$ & $\begin{array}{l}0.824- \\
0.915\end{array}$ & $\begin{array}{l}\text { 3G LTE } \\
\text { (Variable } \\
\text { envelope) }\end{array}$ & 3.3 & 26.7 & 34.2 & 31.2 & $\begin{array}{l}\text { ACLR = - } \\
35.2 \mathrm{dBc}\end{array}$ & 1.41 & $\mathrm{~F}$ & $\mathrm{NO}$ & $\begin{array}{l}\text { OFF chip OMN and } \\
\text { feedback }\end{array}$ \\
\hline [13] & $\begin{array}{l}0.13 \mu \mathrm{m} \\
\text { CMOS }\end{array}$ & $0.7-1.2$ & $\begin{array}{l}\text { Constant } \\
\text { envelope }\end{array}$ & 4.8 & $24.6-20.1$ & $\begin{array}{l}48.3- \\
30\end{array}$ & $\begin{array}{l}16.5- \\
14.9\end{array}$ & N/A & 2.25 & $\mathrm{~F}$ & $\begin{array}{l}\text { Switched } \\
\text { capacitor } \\
\text { bank OMN } \\
\end{array}$ & $\begin{array}{l}\text { Fully Integrated } \\
\text { Tuning for frequency } \\
\text { adjustment }\end{array}$ \\
\hline [14] & $\begin{array}{l}0.25 \mu \mathrm{m} \\
\text { CMOS }\end{array}$ & 1.4 & $\begin{array}{l}\text { Constant } \\
\text { envelope }\end{array}$ & 1.5 & $8.5-24.8$ & 49 & NA & N/A & 0.43 & $\mathrm{~F}$ & $\mathrm{NO}$ & $\begin{array}{l}\text { Fully Integrated } \\
\text { Parallel combination of } \\
3 \text { amplifiers }\end{array}$ \\
\hline [11] & $\begin{array}{l}0.2 \mu \mathrm{m} \\
\mathrm{CMOS} \\
\end{array}$ & 900 & $\begin{array}{l}\text { Constant } \\
\text { envelope }\end{array}$ & $\begin{array}{l}1.8- \\
3 \\
\end{array}$ & 31.8 & 43 & NA & N/A & 2.0 & $\mathrm{~F}$ & $\mathrm{NO}$ & Fully integrated \\
\hline [16] & $\begin{array}{l}0.6 \mu \mathrm{m} \\
\mathrm{CMOS}\end{array}$ & 1.9 & $\begin{array}{l}\text { Constant } \\
\text { envelope }\end{array}$ & 3 & 22.8 & 42 & 10.5 & $\begin{array}{l}\text { IIP3 }=19.5 \\
\mathrm{dBm} \\
\mathrm{THD}=4 \%\end{array}$ & N/A & $\mathrm{F}$ & $\mathrm{NO}$ & OFF chip OMN \\
\hline [34] & $\begin{array}{l}65 \mathrm{~nm} \\
\text { CMOS }\end{array}$ & $\begin{array}{l}3.10- \\
3.98\end{array}$ & $\begin{array}{l}\text { QPSK/16 } \\
\text { QAM }\end{array}$ & 3 & $\begin{array}{l}27.3(\mathrm{CW}) \\
21.8 \\
(16 \mathrm{QAM}) \\
\end{array}$ & 28.6 & 16.8 & $\begin{array}{l}\mathrm{EVM}=5.6 \% \\
\text { 16QAM }\end{array}$ & 2.087 & $\begin{array}{l}\mathrm{A} \\
\mathrm{lo}\end{array}$ & $\begin{array}{l}\text { Doherty } \\
\text { dulation }\end{array}$ & $\begin{array}{l}\text { Transformer-based } \\
\text { parallel power } \\
\text { combining }\end{array}$ \\
\hline $\begin{array}{l}\text { This } \\
\text { work }\end{array}$ & $\begin{array}{l}0.18 \mu \mathrm{m} \\
\mathrm{CMOS}\end{array}$ & 2.4 & $\begin{array}{l}\mathrm{WiFi} \\
\text { (Variable } \\
\text { envelope) } \\
\end{array}$ & $3-4$ & 1919.2 & 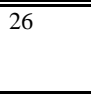 & 111.5 & $\begin{array}{l}\text { ACLR }=- \\
29.8 \mathrm{dBc} \\
\text { THD }=4.9 \% \\
\end{array}$ & 2.56 & 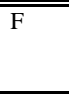 & $\begin{array}{l}\text { MOS } \\
\text { varactors } \\
\text { OMN }\end{array}$ & $\begin{array}{l}\text { Fully integrated. } \\
\text { Tuning for load } \\
\text { (antenna) matching } \\
\end{array}$ \\
\hline
\end{tabular}

reduced, which is also confirmed by the ACLR data presented in Table I. For $Z_{\mathrm{LA} 6}$ the lower channel ACLR is reduced by 5 dB. A similar reduction can be observed for other mismatched loads. At highest $P_{\text {out }}$ levels (optimum PAE) it can be observed that ACLR is $-29.8 \mathrm{dBc}$, a better value than with matched output load. This results show that the OMN tuner is able to not only match the switch-mode PA to antenna variations but also improve distortion and back-off characteristics. Regarding the EVM, in Fig. 15 it can be observed that in tuned condition under mismatched (antenna) load impedances, the EVM values improve up to $3 \%$ with respect to the nottuned state, completely recovering the featured EVM levels in the $50 \Omega$ load case.

Table III shows a comparison of the PA presented in this paper with other PAs in the bibliography. Most PAs are not reconfigurable. The proposed design exhibits a PAE which is smaller than in [13] (frequency-reconfigurable design) and in the not-reconfigurable designs of [11], [14], [16] and [19], but the center frequencies are substantially lower $(1.2 \mathrm{GHz}, 0.9$ $\mathrm{GHz}, 1.4 \mathrm{GHz}, 1.2 \mathrm{GHz}$ and $0.915 \mathrm{GHz}$ respectively). Furthermore, in [14] bondwires are used to implement the required inductors, thus avoiding the loss associated to spiral inductors, and in [19] bondwires, SMD capacitors and SMD inductors are used. In [16], a partially off-chip output matching network is used (bondwire and SMD capacitor). The PAE of the Class-E power amplifier reported in [5] is $40.6 \%$ at $5 \mathrm{GHz}$, but it is using an injection-locking technique. Concerning the gain of the proposed power amplifier, it is similar to the amplifier reported in [16] $(10.5 \mathrm{~dB}$ at $1.9 \mathrm{GHz})$ and in [13] (14.9 dB at the frequency $1.2 \mathrm{GHz}$, which is lower than $2.4 \mathrm{GHz}$ ). Compared to [4] and [19], it is smaller (19 dB at $2.4 \mathrm{GHz}$, and $31.2 \mathrm{~dB}$ at $0.915 \mathrm{GHz}$, respectively), but in
[4] and [19] multistage designs are used. Concerning the area of the proposed power amplifier, it is smaller than that of [6], very similar to [13], and bigger than that of [11], [14] and [19], but the designs of [11], [14] and [19] are not reconfigurable. Among the reconfigurable designs, reconfiguration responds to different criteria (frequency band in [13] and DC power in [6]) than the load (antenna) variation criteria proposed in this paper. Only in [34] an efficiency enhancement is provided against antenna mismatch, but the allowed load mismatch (2:1 VSWR) is smaller than in the design proposed in this paper (3:1 VSWR, corresponding to $\left(\left|\Gamma_{\mathrm{LA}}\right|=0.5\right)$. To the authors' knowledge, the PA presented is the only integrated class-F PA aimed to continuous load variation adjustment at fundamental frequency (without affecting harmonic tuning) using MOS varactors, and has an excellent balance between output power, PAE and distortion.

The OMN tuner proposed in this paper could be automated in order not to require human intervention. This requires knowledge of the instantaneous (real time) value of the (antenna) load impedance, which in turn can be accomplished by adding elements for impedance-sensing and actuation of the MOS varactors in the OMN tuner shown in Fig. 6. A possible configuration of this system is shown in the block diagram of Fig. 19, which can be easily fabricated using commercially-available integrated circuits, and also it would be possible to integrate the full system in CMOS to obtain an on-chip solution. The system includes a directional coupler, two peak detectors, a phase comparator, and a digital microcontroller system which incorporates $\mathrm{A} / \mathrm{D}$ and $\mathrm{D} / \mathrm{A}$ blocks, a CPU, the stored look-up table values of Fig. 5(a), and a control algorithm. The directional coupler could be implemented using lumped elements [35] to save area. The 
impedance detector consists of two peak detectors and a phase comparator, delivering a very-low frequency signal containing the amplitude and phase information of the incident and reflected waves, respectively. A possible CMOS vectordetector configuration is reported in [36]. A raw measurement of the (antenna) load reflection coefficient is obtained from the complex ratio between detected incident and reflected waves, $M=\left|M_{\text {ref }} / M_{i n c}\right| e^{j \phi_{M}}$. In order to de-embed the actual antenna reflection coefficient $\Gamma_{L A}=\left|\Gamma_{L A}\right| e^{j \phi_{L A}}$ a mathematical correction is applied to $M$, which takes into account the effect of the directional coupler and the loads of coupled ports $\left(\Gamma_{\text {ref }}\right.$ and $\Gamma_{\text {inc }}$ in Fig. 19). The digital control system compares the measured (corrected) antenna reflection coefficient values with the load values stored in a look-up table jointly with the actuation-voltages plotted in Fig. 5(b). Using an algorithm for estimation of minimum distance, the closest impedance value in the look-up table is selected, and the corresponding actuation voltages $\mathrm{V}_{\text {ctl1 }}$ and $\mathrm{V}_{\text {ctt2 }}$ are used to tune the varactors automatically. This procedure is repeated for any antenna reflection coefficient (which is time-varying due to hand and body effects). In this way the tuner could be controlled automatically in real time. The estimated overhead produced by a control system such as the one illustrated in Fig. 19 is low. Excluding the micro-controller it is less than $1 \%$ of the PA power consumption and around $15 \%$ of die area [37], and including the microcontroller it would be around $2 \%$ of the PA power consumption.

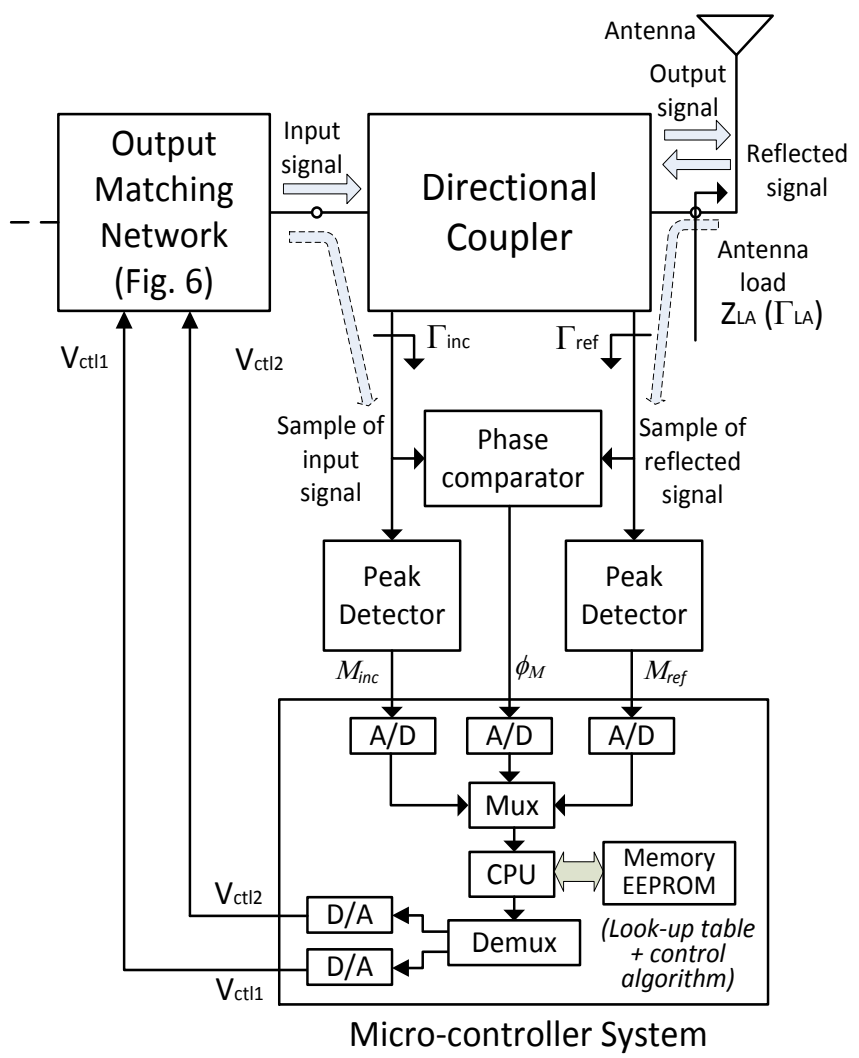

Fig. 19. Possible block diagram for an impedance-sensing and varactoractuation system to automatize the control of the proposed OMN tuner.

\section{CONCLUSION}

In this work, a novel reconfigurable CMOS class-F power amplifier at $2.4 \mathrm{GHz}$ with up to $3^{\text {rd }}$ harmonic tuning has been presented. It is able to match load variations caused by hand and body effect on the antenna. The amplifier measurements for a nominal load impedance of $50 \Omega$ show an optimal PAE of $26 \%$, a THD of $4.9 \%$, and ACLR of $-26.9 \mathrm{~dB}$ while delivering an output power of $18.7 \mathrm{dBm}$. Load (antenna) variations are compensated by using an impedance tuner in the amplifier output matching network which integrates two RF MOS variable capacitors. The measured results for mismatched loads show that the impedance tuner is able to continuously tune load reflection coefficients with a magnitude up to 0.5 maintaining a tuned PAE better than $18.6 \%$, in the phase range $\left[+90^{\circ},-90^{\circ}\right]$, with an output power higher than $17.5 \mathrm{dBm}$. The maximum tuned PAE and output power are $19.2 \mathrm{dBm}$ and $19.9 \%$ respectively which coincides with the result in the matched output load condition. Also in the tuned condition the PA is able to compensate the nonlinear distortion. The measured lower channel ACLR for mismatched loads is reduced by $5 \mathrm{~dB}$ with respect to the nottuned condition, reaching $-29.8 \mathrm{dBc}$ for an output power of 18 $\mathrm{dBm}$ (maximum PAE). Thus the proposed reconfigurable tuner circuit concept is validated, showing that it is able to successfully compensate the effect of load variation on the power amplifier performance.

\section{ACKNOWLEDGMENT}

The authors wish to thank the HIPICS research group of UPC, for their support to access the $0.18 \mu \mathrm{m}$ CMOS technology and Cadence Software and to the technical staff of Dept. TSC (UPC) in preparing the samples for measurement.

\section{REFERENCES}

[1] D. Buss, "Device issues in the integration of analog/RF functions in deep submicron digital CMOS," International Electron Devices Meeting. IEDM '99. Technical Digest., pp. 423-426, Dec 1999.

[2] A. M. Niknejad, D. Chowdhury, and J. Chen, "Design of CMOS power amplifiers," IEEE Trans. Microw. Theory Tech., vol. 60, no. 6, pp. 17841796, June 2012.

[3] S. C. Cripps, "RF power amplifiers for wireless communications", second edition, Artech House, 2006.

[4] M. M. El-Desouki, S. M. Abdelsayed, M. J. Deen, N. K. Nikolova, and Y. M. Haddara, "The impact of On-Chip interconnections on CMOS RF integrated circuits," IEEE Trans. Electron Devices, vol. 56, no. 9, pp. 18821890, Sept 2009.

[5] Y. Yamashita, D. Kanemoto, H. Kanaya, R. K. Pokharel, and K. Yoshida, "A CMOS class-E power amplifier of $40 \% \mathrm{PAE}$ at $5 \mathrm{GHz}$ for constant envelope modulation system," IEEE 13th Topical Meeting on Silicon Monolithic Integrated Circuits in RF Systems (SiRF), pp. 66-68, Jan 2013.

[6] V. Bhagavatula, W. C. Wesson, S. K. Shin, and J. C. Rudell, "A fully integrated, regulatorless CMOS power amplifier for long-range wireless sensor communication," IEEE J. Solid-State Circuits, vol. 48, no. 5, pp. 1225-1236, May 2013.

[7] P. Colantonio, F. Giannini, G. Leuzzi, and E. Limiti, "On the class-F power amplifier design," International Journal of RF and Microwave Computer-Aided Engineering, vol. 9, no. 2, pp. 129-149, 1999.

[8] F. H. Raab, "Class-F power amplifiers with maximally flat waveforms," IEEE Trans. Microw. Theory Tech., vol. 45, no. 11, pp. 2007-2012, 1997.

[9] F. Raab, "Class-E, Class-C, and Class-F power amplifiers based upon a finite number of harmonics," IEEE Trans. Microw. Theory Tech., vol. 49, no. 8, pp. 1462-1468, Aug 2001 
[10] M. Gilasgar, A. Barlabe, and L. Pradell, "Highly efficient class-F RF power amplifiers with very low distortion," The Radio Science Bulletin, vol. 347, pp. 21-31, 2013.

[11] T. Kuo and B. Lusignan, "A 1.5W class-F RF power amplifier in $0.2 \mu \mathrm{m}$ CMOS technology," IEEE International Solid-State Circuits Conference (ISSCC). Digest of Technical Papers, pp. 154-155, Feb 2001.

[12] J. Carls, F. Ellinger, U. Joerges, and M. Krcmar, "Highly-efficient CMOS C-band class-F power amplifier for low supply voltages," Electronics Letters, vol. 45, no. 24, pp. 1240-1241, Nov 2009.

[13] K. K. Sessou and N. M. Neihart, "An integrated 700-1200 MHz class-F PA with tunable harmonic terminations in 0.13- $\mu$ m CMOS," IEEE Trans. Microw. Theory Tech., vol. 63, no. 4, pp. 1315-1323, April 2015.

[14] A. Shirvani, D. K. Su, and B. A. Wooley, "A CMOS RF power amplifier with parallel amplification for efficient power control," IEEE J. Solid-State Circuits, vol. 37, no. 6, pp. 684-693, Jun 2002.

[15] K. Benaissa et al., "RF CMOS on high-resistivity substrates for system on-chip applications," IEEE Trans. Electron Devices, vol. 50, no. 3, pp. 567-576, March 2003.

[16] F. Fortes and M. J. do Rosario, "A second harmonic class-F power amplifier in standard CMOS technology," IEEE Trans. Microw. Theory Tech., vol. 49, no. 6, pp. 1216-1220, Jun 2001

[17] B. Francois and P. Reynaert, "A fully integrated watt-level linear 900MHz CMOS RF power amplifier for LTE-applications," IEEE Trans. Microw. Theory Tech., vol. 60, no. 6, pp. 1878-1885, June 2012.

[18] E. Kaymaksut and P. Reynaert, "A dual-mode transformer-based Doherty LTE power amplifier in 40nm CMOS," IEEE International Solid-State Circuits Conference Digest of Technical Papers (ISSCC), pp. 64-65, Feb 2014.

[19] J. H. Kim and C. S. Park, "A feedback technique to compensate for AMPM distortion in linear CMOS class-F power amplifier," IEEE Microw. Wireless Compon. Lett., vol. 24, no. 10, pp. 725-727, Oct 2014.

[20] K. Kanda et al., "A fully integrated triple-band CMOS power amplifier for WCDMA mobile handsets," IEEE International Solid-State Circuits Conference, pp. 86-88, Feb 2012.

[21] J. H. Chen, S. R. Helmi, H. Pajouhi, Y. Sim, and S. Mohammadi, "A wideband RF power amplifier in 45-nm CMOS SOI technology with substrate transferred to AIN," IEEE Trans. Microw. Theory Tech., vol. 60, no. 12, pp. 4089-4096, Dec 2012.

[22] K. Boyle and M. Leitner, "Mobile phone antenna impedance variations with real users and phantoms," International Workshop on Antenna Technology (iWAT), pp. 420-423, March 2011.

[23] K. Boyle, Y. Yuan, and L. Ligthart, "Analysis of mobile phone antenna impedance variations with user proximity," IEEE Trans. Antennas Propag., vol. 55, no. 2, pp. 364-372, Feb 2007.

[24] Z. Zhou and K. Melde, "Frequency agility of broadband antennas integrated with a reconfigurable RF impedance tuner," IEEE Antennas Wireless Propag. Lett., vol. 6, pp. 56-59, 2007.

[25] F. Carrara, C. D. Presti, F. Pappalardo, and G. Palmisano, "A 2.4-GHz 24-dBm SOI CMOS power amplifier with fully integrated reconfigurable output matching network," IEEE Trans. Microw. Theory Tech., vol. 57, no. 9, pp. 2122-2130, Sept 2009.

[26] P. Sjoblom and H. Sjoland, "An adaptive impedance tuning CMOS circuit for ISM 2.4-GHz band," IEEE Trans. Circuits Syst. I, vol. 52, no. 6, pp. 1115-1124, June 2005.

[27] G. Lee, J. Jung, and J. I. Song, "A multiband power amplifier with a reconfigurable output-matching network for $10-\mathrm{MHz}$ BW LTE mobile phone applications," IEEE Trans. Circuits Syst. II, vol. 62, no. 6, pp. 558562, June 2015.

[28] — - "A SiGe BiCMOS power amplifier using a lumped element-based impedance tuner," IEEE Microw. Wireless Compon. Lett., vol. 26, no. 1, pp. 58-60, Jan 2016.

[29] G. Liu, P. Haldi, T. J. K. Liu, and A. M. Niknejad, "Fully integrated CMOS power amplifier with efficiency enhancement at power back-Off," IEEE J. Solid-State Circuits, vol. 43, no. 3, pp. 600-609, March 2008.

[30] Y. Yoon et al., "A dual-mode CMOS RF power amplifier with integrated tunable matching network," IEEE Trans. Microw. Theory Tech., vol. 60, no. 1, pp. 77-88, Jan 2012.

[31] R. Paul, L. Sankey, L. Corradini, Z. Popovic, and D. Maksimovic, "Power management of wideband code division multiple access RF power amplifiers with antenna mismatch," IEEE Trans. Power Electron, vol. 25, no. 4, pp. 981-991, April 2010.

[32] A. van Bezooijen, M. A. de Jongh, F. van Straten, R. Mahmoudi, and A. H. M. van Roermund, "Adaptive impedance-matching techniques for controlling L networks," IEEE Trans. Circuits Syst. I, vol. 57, no. 2, pp. 495-505, Feb 2010.
[33] S. Hu, S. Kousai, and H. Wang, "A Compact Broadband Mixed-Signal Power Amplifier in Bulk CMOS With Hybrid Class-G and Dynamic Load Trajectory Manipulation," IEEE Journal of Solid-Sate Circuits, vol. 52, no. 6, pp. 1463-1478, Jun. 2017.

[34] S. Hu, S. Kousai, J. S. Park, O. L. Chlieh, H. Wang, "Design of A Transformer-Based Reconfigurable Digital Polar Doherty Power Amplifier Fully Integrated in Bulk CMOS," IEEE Journal of Solid-Sate Circuits, vol. 50, no. 5, pp. 1094-1106, May 2015.

[35] J. Jung, G. Lee, and J.-I. Song, "A Lumped-Element Directional Coupler With High Isolation for Mobile RFID Reader," IEEE Microw. Wireless Compon. Lett., vol. 24, no. 6, pp. 382-384, June 2014.

[36] D. Nicolas, A. Serhan, A. Giry, T. Parra, E. Mercier, "A Fully-Integrated SOI CMOS Complex-Impedance Detector for Matching Network Tuning in LTE Power Amplifier," IEEE Radio Frequency Integrated Circuits Symposium, pp. 15-18, June 2017.

[37] E. de Foucauld, R. Severino, D. Nicolas, A. Giry and C. Delaveaud, "A $433 \mathrm{MHz}$ SOI CMOS automatic impedance matching circuit," IEEE Transactions on Circuits and Systems II: Express Briefs, 2018 (Early Access).

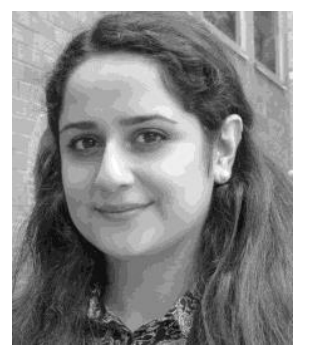

Mitra Gilasgar received the Ph.D. degree in telecommunication engineering from Universitat Politècnica de Catalunya (UPC), Barcelona, Spain in 2017. During her career, she has been involved in the design of RF front-end building blocks and transceiver architectures with the focus on integration in CMOS technology. She joined UPC in 2010 as a researcher working on millimeterwave ICs and in 2011 she was awarded the Spanish FPI grant to work on high-efficiency power amplifier architectures in CMOS and MEMS technologies. During 2013, she was a visiting student in CIRFE at the University of Waterloo, where she worked on the design of tuners and MEMS capacitors. Since 2016, she has been an RF design and development engineer at Ampleon, the Netherlands, working on high power transistor designs. Her current research interests include CMOS circuit design, RF front-end MMICs and RF power amplifiers

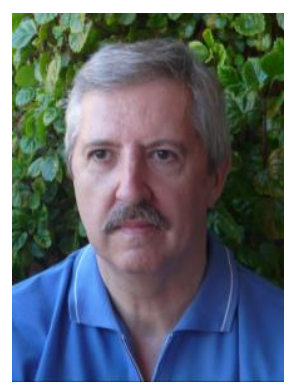

Antoni Barlabé (S'82-M'86) was born in Barcelona, Catalonia. He received the M.S. and Ph.D. degrees in Telecommunications Engineering from Universitat Politècnica de Catalunya (UPC) in 1986 and 1996, respectively. $\mathrm{He}$ is currently an Associate Professor with the Department of Signal Theory and Communications in UPC, where he has been teaching microwave and antenna engineering and communication electronics in Telecommunication Engineering degrees. Being also an airplane pilot, he is actually teaching aeronautic radio-navigation systems in Aerospace Engineering degrees. From 2002 to 2006 he was the Director of the Telecommunications Division at the Technological Research Center of Vilanova i la Geltrú (Barcelona). His current research interests include numerical methods for microwave and millimeter-wave structures, RF-MEMS and non-linear microwave amplifiers.

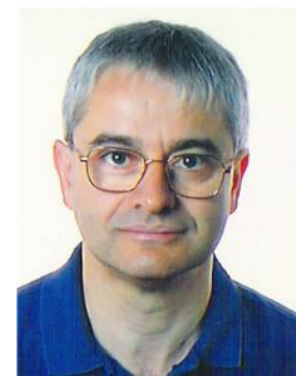

Lluís Pradell (M'86) received the M.S. and PhD. degrees in Telecommunication Engineering from the Universitat Politècnica de Catalunya (UPC), Barcelona, Catalonia, Spain, in 1981 and 1989, respectively. From 1981 to 1985 , he was with Mier-Allende, Barcelona, as an RF and Microwave Engineer. In 1985, he joined the faculty of UPC, and became a Full Professor in 2005. His research topics include microwave/millimeter-wave amplifiers in CMOS and BiCMOS technologies, on-wafer measurement and calibration techniques, millimeter-wave systems, multimodal models for uniplanar structures/transitions, and RF-MEMS devices/applications. 